\title{
Processing Routes to Macroporous Ceramics: A Review
}

\author{
André R. Studart, ${ }^{\dagger}$ Urs T. Gonzenbach, Elena Tervoort, and Ludwig J. Gauckler \\ Department of Materials, ETH Zurich, 8093 Zurich, Switzerland
}

\begin{abstract}
Macroporous ceramics with pore sizes from $400 \mathrm{~nm}$ to $4 \mathrm{~mm}$ and porosity within the range $\mathbf{2 0 \%}-\mathbf{9 7 \%}$ have been produced for a number of well-established and emerging applications, such as molten metal filtration, catalysis, refractory insulation, and hot gas filtration. These applications take advantage of the unique properties achieved through the incorporation of macropores into solid ceramics. In this article, we review the main processing routes that can be used for the fabrication of macroporous ceramics with tailored microstructure and chemical composition. Emphasis is given to versatile and simple approaches that allow one to control the microstructural features that ultimately determine the properties of the macroporous material. Replica, sacrificial template, and direct foaming techniques are described and compared in terms of microstructures and mechanical properties that can be achieved. Finally, directions to future investigations on the processing of macroporous ceramics are proposed.
\end{abstract}

\section{Introduction}

$\mathrm{M}$ ATERIALS containing tailored porosity exhibit special properties and features that usually cannot be achieved by their conventional dense counterparts. Therefore, porous materials find nowadays many applications as end products and in several technological processes. Macroporous materials are used in various forms and compositions in everyday life, including for instance polymeric foams for packaging, aluminum light-weight structures in buildings and airplanes, as well as porous ceramics for water purification.

Contrary to metallic and polymeric porous structures, pores have been traditionally avoided in ceramic components because of their inherently brittle nature. However, an increasing number of applications that require porous ceramics have appeared in the last decades, especially for environments where high temperatures, extensive wear and corrosive media are involved. Such applications include for example the filtration of molten

G. Messing — contributing editor

\footnotetext{
Manuscript No. 21435. Received January 30, 2006; approved March 03, 2006.

The investigations on particle-stabilized foams was supported by the CIBA Specialty Chemicals (Switzerland).

Presented at the 9th International Ceramic Processing Science Symposium, Coral Springs, FL, Jan. 8-11, 2006.

${ }^{\dagger}$ Author to whom correspondence should be addressed. e-mail: andre.studart@mat. ethz.ch
}

metals, high-temperature thermal insulation, support for catalytic reactions, filtration of particulates from diesel engine exhaust gases, and filtration of hot corrosive gases in various industrial processes. ${ }^{1-3}$ The advantages of using porous ceramics in these applications are usually the high melting point, tailored electronic properties, high corrosion, and wear resistance in combination with the features gained by the replacement of solid material by voids in the component. Such features include low thermal mass, low thermal conductivity, controlled permeability, high surface area, low density, high specific strength, and low dielectric constant.

These properties can be tailored for each specific application by controlling the composition and microstructure of the porous ceramic. Changes in open and closed porosity, pore size distribution, and pore morphology can have a major effect on a material's properties. All of these microstructural features are in turn highly influenced by the processing route used for the production of the porous material.

The most straightforward processing route for the preparation of porous ceramics is the partial sintering of initially porous powder compacts or the sintering of powder mixtures which undergo solid state reactions that lead to pore formation. ${ }^{4,5}$ This method often results in a relatively low porosity $(<60 \mathrm{vol} \%)$, with pores homogeneously distributed within the microstructure.

In addition to such a straightforward approach, many novel methods for the preparation of porous ceramics with controlled microstructure have been developed in response to the increasing number of new potential applications for cellular ceramics. ${ }^{2}$ Versatile techniques that allow one to deliberately tune the porosity, pore morphology and size distribution, and that can additionally be applied to ceramic materials of many different chemical compositions are especially demanded. Novel applications where specific chemical compositions and tailored microstructures are required include electrodes and supports for batteries and solid oxide fuel cells, scaffolds for bone replacement and tissue engineering, heating elements, chemical sensors, solar radiation conversion, among others. ${ }^{1,2,6}$

The main processing methods used for the preparation of cellular ceramics such as foams, honeycomb structures and interconnected rods, fibers and hollow spheres were recently reviewed by Colombo. ${ }^{7}$ The fabrication and use of cellular ceramics in a vast number of different fields has also been described in a recent book edited by Scheffler and Colombo. ${ }^{2}$ While this valuable literature contains extensive information on the production and applications of cellular ceramics, the processing-microstructure-property relations for each of the main

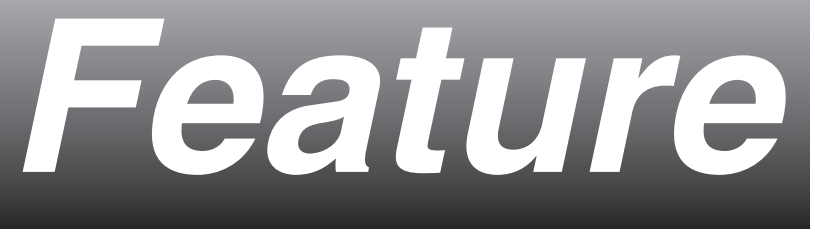


processing routes has not been fully explored. ${ }^{8}$ A thorough understanding of these relations would greatly aid the selection of processing techniques that can provide the final microstructure and properties required for each specific application.

The aim of this article is to compare some of the processing routes currently available for the preparation of macroporous ceramics (i.e., pore size $>50 \mathrm{~nm}$ ), with particular emphasis on the processing-microstructure-property relations inherent to each process. We also present a simple and versatile processing method recently developed by the authors that has not been included in previous reviews.

Because of the large number of articles in the field, we focus mainly on macroporous ceramics that exhibit total porosity higher than $50 \mathrm{vol} \%$. We adopt here the nomenclature recommended by the IUPAC, ${ }^{9}$ according to which macroporous materials are those exhibiting pore width $(d)$ larger than 50 $\mathrm{nm}$. Recent articles on the processing of micro- $(d<2 \mathrm{~nm})$ and mesoporous $(2 \mathrm{~nm}<d<50 \mathrm{~nm})$ ceramic materials using a number of sol-gel, templating, and other chemistry routes can be found in the literature. ${ }^{10-12}$ For reasons given above, honeycomb structures, interconnected rods, fibers, hollow spheres, and porous materials prepared by solid freeform fabrication techniques have not been included in this article. However, Karp ${ }^{13}$ Lee, ${ }^{14}$ Michna, ${ }^{15}$ Colombo ${ }^{7}$ and Scheffler ${ }^{2}$ are suggested for those interested in these important cellular structures. It is also worth noting that even though we gathered many examples to illustrate some of the processing routes developed so far, a number of other approaches can be found in the recent literature using similar concepts to those outlined here.

The processing routes described in this article have been classified into replica, sacrificial template and direct foaming methods, as schematically illustrated in Fig. 1. The processing features of each of these methods are thoroughly discussed and compared with regards to the versatility and ease of fabrication, as well as their influence on the microstructure and mechanical strength of the final macroporous ceramics. Finally, we summarize the main characteristics of the processing routes described and provide directions for future advances on this field.

\section{Replica Technique}

The replica method is based on the impregnation of a cellular structure with a ceramic suspension or precursor solution in order to produce a macroporous ceramic exhibiting the same morphology as the original porous material (Fig. 1(a)). Many synthetic and natural cellular structures can be used as templates to fabricate macroporous ceramics through the replica technique. Here, we focus mainly on those processes that allow for the fabrication of bulk ceramic structures, while references are given for the recent studies describing the preparation of ceramic macroporous films and particles.

\section{(1) Synthetic Templates}

The replica technique is in fact considered as the first method deliberately used for the production of macroporous ceramics. The original invention dates back to the early 1960s, when Schwartzwalder and Somers ${ }^{16}$ started using polymeric sponges as templates to prepare ceramic cellular structures of various pore sizes, porosities, and chemical compositions. Since then the sponge replica technique has become the most popular method to produce macroporous ceramics and is today extensively used in industry to prepare ceramic filters for molten metal filtration ${ }^{3}$ and other applications. This success is primarily attributed to the simplicity and flexibility of the method.

In the polymer replica approach, a highly porous polymeric sponge (typically polyurethane) is initially soaked into a ceramic suspension until the internal pores are filled in with ceramic material. The impregnated sponge is then passed through rollers to remove the excess suspension and enable the formation of a thin ceramic coating over the struts of the original cellular structure. At this stage, the slurry has to be sufficiently fluid to be partially removed under the shearing conditions applied by the rollers, but the remaining ceramic wet coating should be viscous enough to avoid dripping. Therefore, ceramic suspensions exhibiting shear-thinning behavior are needed to efficiently coat the polymeric template. Suspensions exhibiting a viscosity decrease from 10-30 $\mathrm{Pa} \cdot \mathrm{s}$ at a shear rate of $5 \mathrm{~s}^{-1}$ down to 1-6 $\mathrm{Pa} \cdot \mathrm{s}$ at a shear rate of $100 \mathrm{~s}^{-1}$ have been shown to be suitable for this process. ${ }^{17-19}$ This shear-thinning behavior is achieved using thixotropic and thickening additives such as clays, colloidal silica, carboxymethyl cellulose, and polyethylene oxide in combination with conventional dispersants. ${ }^{19-23}$

The ceramic-coated polymeric template is subsequently dried and pyrolysed through careful heating between $300^{\circ}$ and $800^{\circ} \mathrm{C}^{21}$ Heating rates usually lower than $1^{\circ} \mathrm{C} / \mathrm{min}$ are required in this step to allow for the gradual decomposition and diffusion of the polymeric material, avoiding the build-up of pressure within the coated struts. ${ }^{21}$ Binders and plasticizers are added to the initial suspension in order to provide ceramic coatings sufficiently strong to prevent cracking the struts during pyrolysis. Typical binders used are colloidal aluminum orthophosphate, potassium and sodium silicates, magnesium orthoborate, hydratable alumina, colloidal silica, polyvinyl butyral with polyethylene glycol as plasticizer, and polymerizable monomers. ${ }^{19-21,24}$ After removal of the polymeric template, the ceramic coating is finally densified by sintering in an appropriate atmosphere at temperatures ranging from $1100^{\circ}$ to $1700^{\circ} \mathrm{C}$ depending on the material.

Macroporous ceramics of many different chemical compositions have been prepared using the sponge replica technique, as illustrated in Table I. Descriptions of several other possible chemical compositions can be found in the extensive patent literature gathered by Saggio-Woyansky et $a .^{21}$ The great flexibility of the method is partly because of the fact that it is applicable to any ceramic material that can be appropriately dispersed into a suspension. Various $\mathrm{SiC}$-based porous ceramics have also been recently produced by replacing the ceramic suspension with preceramic polymers ${ }^{33-37}$ (Table I). Alternatively, Sherman et al. ${ }^{38}$ developed a similar process to the original replica method, where the polymeric sponge is first converted into a vitreous carbon skeleton and is subsequently infiltrated with reactive gaseous species to form macroporous ceramics of many different carbides, oxides, borides, nitrides, and silicides (Table I).

Porous ceramics obtained with the sponge replica method can reach total open porosity levels within the range $40 \%-95 \%$ and are characterized by a reticulated structure of highly interconnected pores with sizes between $200 \mu \mathrm{m}$ and $3 \mathrm{~mm}$, as outlined in Figs. 2 and 3(a). The high pore interconnectivity enhances the permeability of fluids and gases through the porous structure, ${ }^{66}$ making these reticulated materials very suitable for high through-put filtration.

The minimum cell size of replica-derived porous ceramics is however limited to approximately $200 \mu \mathrm{m}$ (Fig. 2), because of the difficulty with impregnating polymeric sponges with excessively narrow cells. ${ }^{22}$ Predominantly open porous structures are produced with this method, as the original cellular sponge has to be accessible for the impregnation of the ceramic suspension or precursor. However, the ratio of open to closed pores in the final ceramic foam may be adjusted to a certain extent by controlling the suspension viscosity and shear thinning behavior.

A disadvantage of the sponge replica technique is the fact that the struts of the reticulated structure are often cracked during pyrolysis of the polymeric template (Fig. 3(b)), markedly degrading the final mechanical strength of the porous ceramic. ${ }^{68}$ Figure 4 shows that the strut flaws reduce the compressive strength of replica-derived porous ceramics to levels usually lower than the strength theoretically predicted for open cell structures. ${ }^{76}$ Many attempts have been made to avoid this shortcoming by, for instance, improving the wetting of the suspension on the sponge with the help of additives, ${ }^{21,25}$ performing a second impregnation step to fill the cracks in the ceramic struts, ${ }^{17-19,22}$ and introducing fibers ${ }^{77,28}$ or reactive compounds ${ }^{25}$ to enhance the material's 


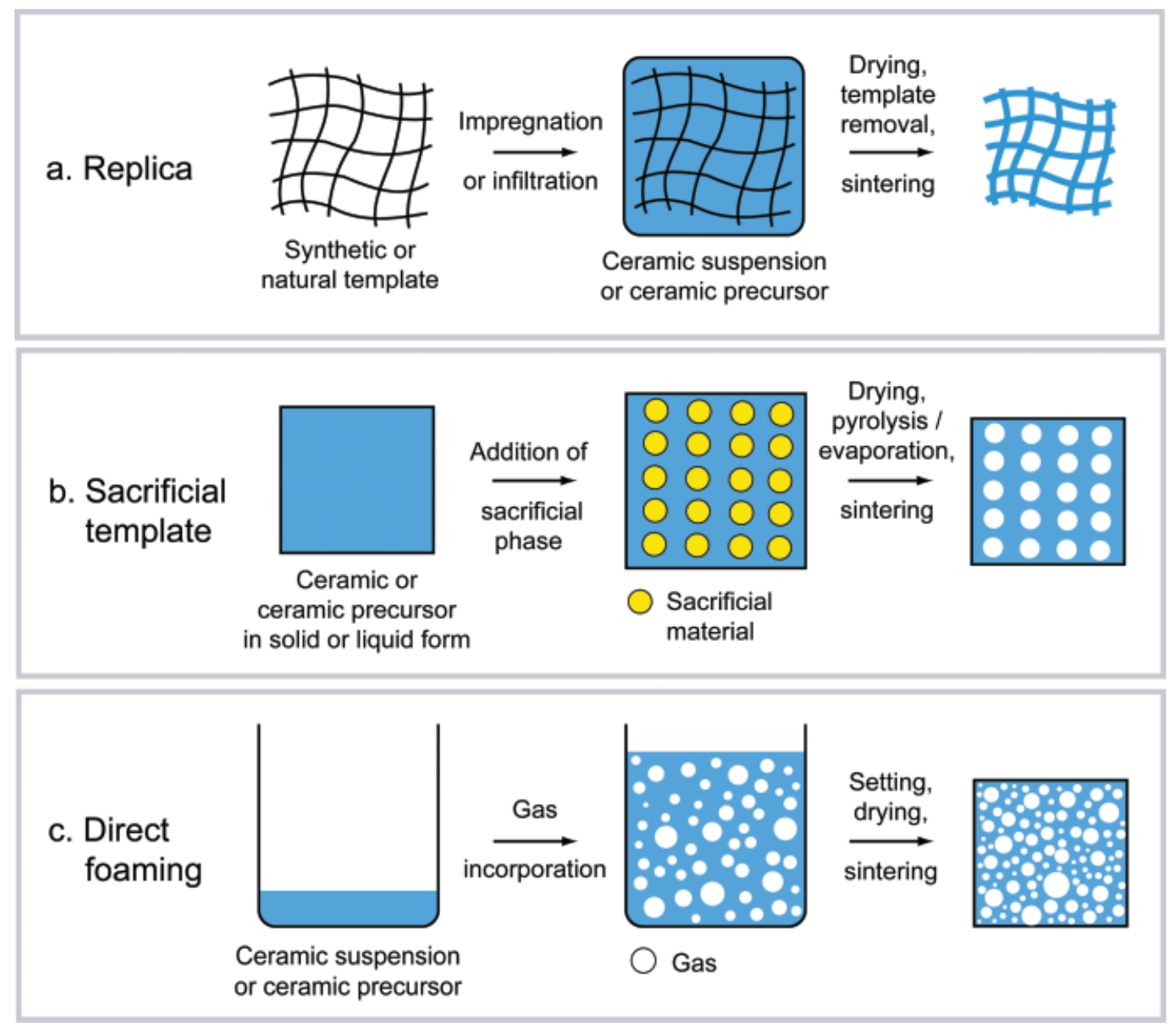

Fig. 1. Scheme of possible processing routes used for the production of macroporous ceramics.

Table I. Examples of Replica Methods Reported in the Literature

Synthetic templates

Polymer Impregnation with ceramic suspension foam

Impregnation with preceramic polymer

Carbon Chemical vapor infiltration (CVI) and foam deposition (CVD) ${ }^{38}$

Natural templates

Coral Impregnation with ceramic suspension Hydrothermal reactions

Sol-gel chemistry

Wood Sol-gel using metal salts, hydroxides, or alkoxides

Infiltration of molten metal

Vapor infiltration and reaction with gaseous metals or metal precursors (CVI)

Impregnation with ceramic suspensions Impregnation with preceramic polymers Liquid precipitation of precursors
$\mathrm{Al}_{2} \mathrm{O}_{3}{ }^{21,25,26}$ reaction bonded $\mathrm{Al}_{2} \mathrm{O}_{3},{ }^{25,27}$ fiber-reinforced $\mathrm{Al}_{2} \mathrm{O}_{3}$, ${ }^{28}$ $\mathrm{ZrO}_{2},{ }^{26}$ cordierite, ${ }^{21,29} \mathrm{SiC}^{21} \mathrm{Si}_{3} \mathrm{~N}_{4},{ }^{17} \mathrm{SiO}_{2}{ }^{21} \mathrm{TiO}_{2},{ }^{21}$ talc, ${ }^{21} \mathrm{MgO},{ }^{21}$ clay, ${ }^{21} \mathrm{Al}_{2} \mathrm{O}_{3}-\mathrm{ZrO}_{2}$ composite, ${ }^{21,22}$ mullite, ${ }^{20,21,23,25,30} \mathrm{Li}_{2} \mathrm{O}-\mathrm{ZrO}_{2}-$ $\mathrm{SiO}_{2}-\mathrm{Al}_{2} \mathrm{O}_{3}$ glass ceramic, ${ }^{31} \mathrm{SiC}-\mathrm{Al}_{2} \mathrm{O}_{3}-\mathrm{SiO}_{2}$ composites, ${ }^{19}$ calcium phosphate-based composites, ${ }^{24}\left(\mathrm{Ca}_{1-x} \mathrm{Mg}_{x}\right) \mathrm{Zr}_{4}\left(\mathrm{PO}_{4}\right)_{6},{ }^{32}$

$\mathrm{La}_{0.84} \mathrm{Sr}_{0.16} \mathrm{Co}_{0.02} \mathrm{MnO}_{3}{ }^{6}$

$\mathrm{Al}_{2} \mathrm{O}_{3}-\mathrm{SiC}$ composites, ${ }^{33} \mathrm{SiC},{ }^{34-36} \mathrm{SiC}-\mathrm{TiC}$ composites, ${ }^{34} \mathrm{SiC}-\mathrm{Si}_{3} \mathrm{~N}_{4}$ composites $^{34,36,37}$

$\mathrm{SiC}, \mathrm{SiO}_{2}, \mathrm{Si}_{3} \mathrm{~N}_{4}, \mathrm{TiC}, \mathrm{TiN}, \mathrm{TiB}_{2}, \mathrm{TiO}_{2}, \mathrm{ZrC}, \mathrm{ZrN}, \mathrm{ZrO}_{2}, \mathrm{Cr}_{2} \mathrm{O}_{3}$, $\mathrm{Al}_{2} \mathrm{O}_{3}$, among others ${ }^{38}$

$\mathrm{Al}_{2} \mathrm{O}_{3},{ }^{39} \mathrm{PZT}^{40}$

Hydroxyapatite ${ }^{41,42}$

Hydroxyapatite ${ }^{43}$

$\mathrm{Fe}_{2} \mathrm{O}_{3},{ }^{44} \mathrm{TiO}_{2},{ }^{45-48} \mathrm{ZrO}_{2},{ }^{46,47} \mathrm{Al}_{2} \mathrm{O}_{3},{ }^{46,47} \mathrm{SiC},{ }^{49,50} \mathrm{ZrC}-\mathrm{C},{ }^{51} \mathrm{TiC}-\mathrm{C},{ }^{51}$ $\mathrm{SiC}-\mathrm{C}^{51}$

$\mathrm{SiC}^{52-54} \mathrm{Si}-\mathrm{SiC},{ }^{52,55}$ and $\mathrm{Si}-\mathrm{SiC}-$ zeolite $^{56}$ composites

$\mathrm{SiC},{ }^{52,57} \mathrm{Al}_{2} \mathrm{O}_{3},{ }^{58} \mathrm{TiC},{ }^{59,60} \mathrm{SiC}^{61} \mathrm{TiO}_{2}{ }^{59}$

$\mathrm{SiC}^{62}$

SiOC-C composites ${ }^{63}$

Macroporous zeolites, ${ }^{64}$ Calcium phosphate-based composites ${ }^{65}$ 


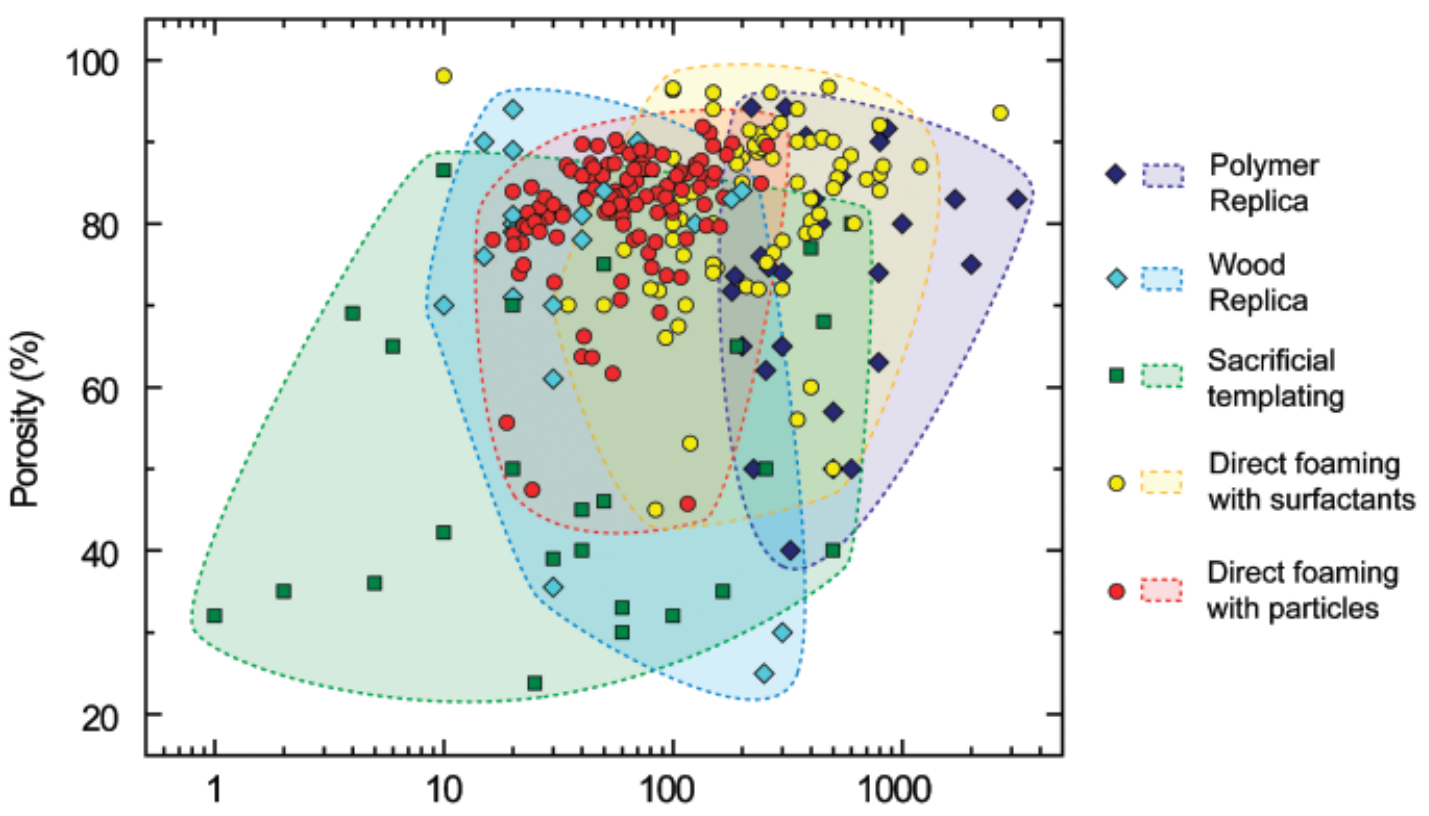

Average pore size $(\mu \mathrm{m})$

Fig. 2. Typical porosity and average pore size achieved via the replica, sacrificial templating, and direct foaming processing routes.

integrity. In contrast to ceramic suspension-derived reticulated structures, cellular materials obtained from preceramic polymers have crack-free struts due most likely to the improved wetting on the sponge and the partial melting of the cross-linked polymer during pyrolysis. ${ }^{33,36}$

\section{(2) Natural Templates}

In addition to synthetic polymer foams, other cellular structures have been used as templates for the fabrication of macroporous ceramics through the replica approach, as outlined in Table I. Cellular structures available in nature are particularly interesting as natural replica templates, due mainly to their special pore morphology and intricate microstructures, which might be difficult to produce artificially.

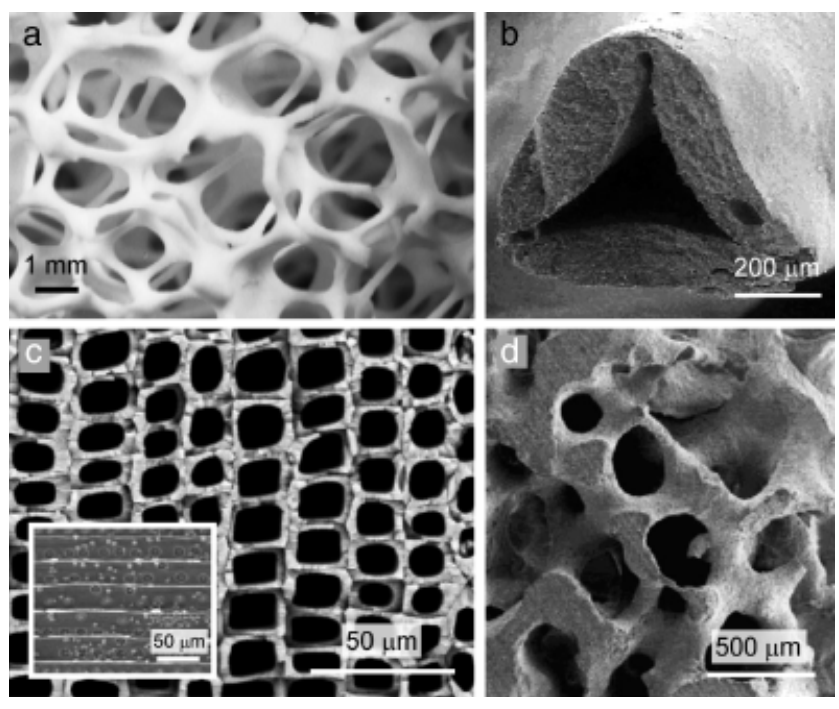

Fig. 3. Microstructures of macroporous ceramics produced via the replica technique. (a) Alumina-based open-cell structure obtained using polyurethane sponge templates, ${ }^{66}$ (b) detail of a strut of a cellular ceramic produced from polymeric sponges, illustrating the typical flaws formed upon pyrolysis of the organic template, ${ }^{67}$ (c) transversal view of a highly-oriented $\mathrm{SiC}$ porous ceramic obtained after infiltration of a wood template with $\mathrm{Si}$ gas (the longitudinal view is shown in the inset) ${ }^{57}$ (d) macroporous hydroxyapatite obtained from a coral structure. ${ }^{43}$
Corals have long been applied as a natural template for the preparation of macroporous ceramic materials, particularly for the production of scaffolds for tissue engineering and bone replacement. ${ }^{41,39}$ In the 1970 s, White et al. ${ }^{39}$ employed a lostwax method named "replamineform" to replicate the structure of corals and other marine invertebrate skeletons. In this technique, the coral is first impregnated with wax under vacuum to obtain a negative form of the cellular structure. After hardening the wax, the calcium carbonate of the coralline skeleton is leached out using a strong acidic solution. The macroporous ceramic is obtained by impregnating the negative wax model with a ceramic suspension and subsequently removing the organic material by pyrolysis. This approach has been successfully used to produce macroporous PZT ceramics with tailored piezoelectric properties. ${ }^{78,40}$ The cellular structure of corals has also been directly converted into macroporous hydroxyapatite scaffolds by submitting the marine skeleton to hydrothermal treatments at high temperatures and pressures ${ }^{41}$ (Fig. 3(d)). This treatment is performed in a phosphate solution, so that the carbonate ions from the aragonite material $\left(\mathrm{CaCO}_{3}\right)$ originally present in the coral are partially or totally replaced by phosphate ions to form hydroxyapatite. ${ }^{41,42}$ Sol-gel chemistry has also been lately used to prepare macroporous hydroxyapatite scaffolds with improved mechanical properties from coral templates. $^{43}$

Following the same biomimetic approach used in the "replamineform" technique, many investigators have studied the transformation of wood cellular structures into macroporous ceramics (Fig. 3(c)). The presence of oriented vessels in the structure of wood enables the preparation of macroporous ceramics with highly anisotropic aligned pores which cannot be achieved with the other replica techniques. ${ }^{49}$

Figure 5 illustrates the processing routes that can be applied to transform wood structures into cellular ceramics. The most common approach is to first prepare a carbon cellular preform by heat treating the wood structure under inert atmosphere at temperatures within $600^{\circ}-1800^{\circ} \mathrm{C}$ (Fig. 5). The carbon preform is subsequently infiltrated with gases or liquids at high temperatures to obtain the macroporous ceramic. Alternatively, the carbon preform is infiltrated at room temperature with liquid sols and afterwards oxidized to render the cellular ceramic (Fig. 5). Table I shows examples of reactants used for infiltration and the resulting composition of the wood-derived macroporous ceramic. 


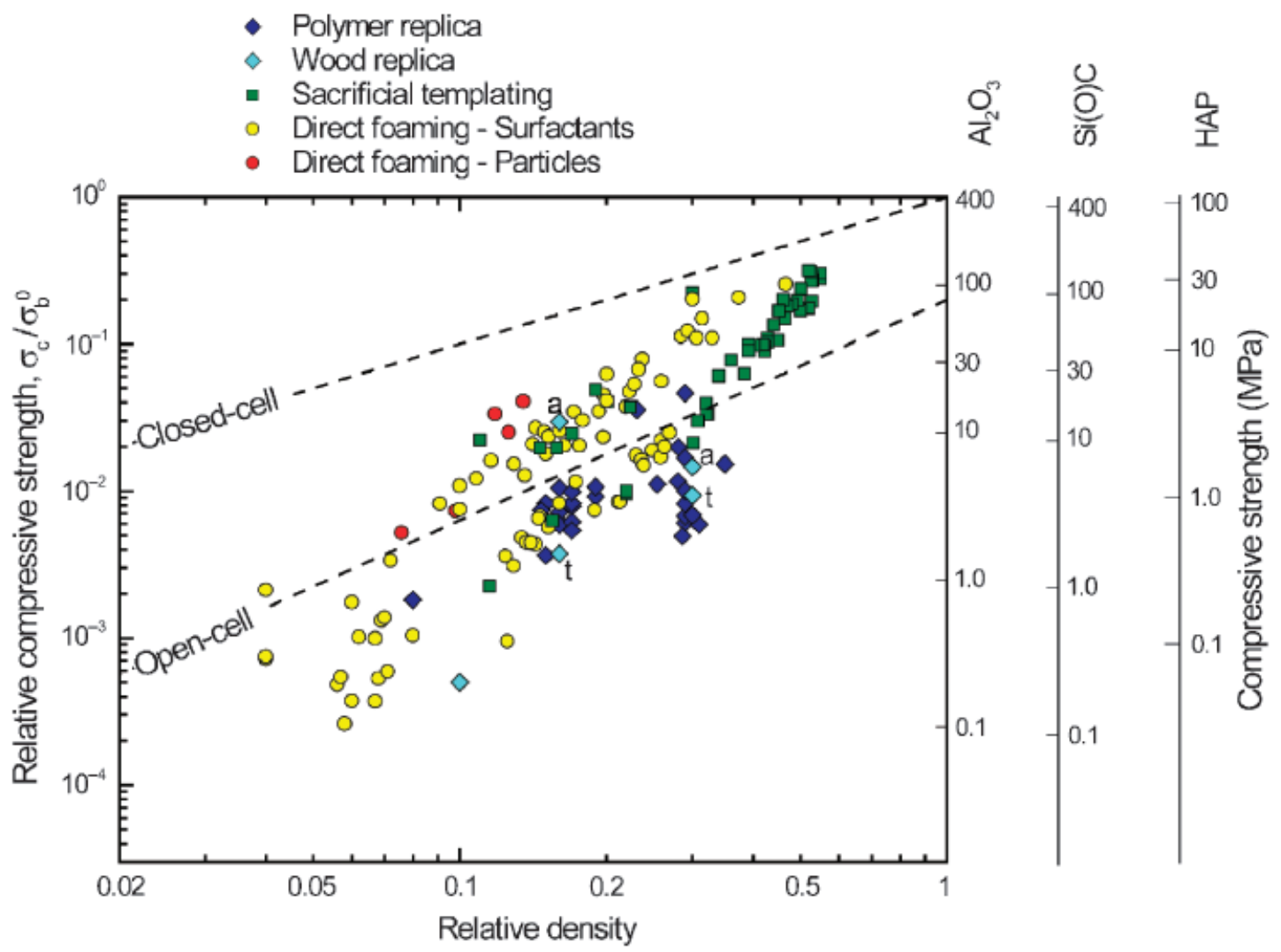

Fig. 4. Relative compressive strength as a function of the relative density of macroporous ceramics produced via replica, sacrificial template and direct foaming methods. The relative strength was calculated from the ratio between the compressive strength of the porous structure $\left(\sigma_{\mathrm{c}}\right)$ and the bending strength of its dense counterpart $\left(\sigma_{\mathrm{b}}^{0}\right)$. The data were obtained from porous ceramics of different chemical compositions, assuming a bending strength of $400,450,450,400,110$, and $320 \mathrm{MPa}$ for the alumina, ${ }^{69}$ silicon carbide, ${ }^{70}$ silicon oxycarbide, ${ }^{71}$ titania, ${ }^{72}$ hydroxyapatite, ${ }^{73}$ and mullite ${ }^{74,75}$ dense materials, respectively. The $y$-scales on the right hand side indicate the corresponding absolute compressive strength for alumina, silicon carbide/ oxycarbide, and hydroxyapatite porous structures. The labels $a$ and $t$ indicate the strength data measured axially and tangentially, respectively, to the aligned pores of wood-derived structures. The relative strength theoretically expected for open- and close-cell porous ceramics according to the model from Gibson and Asbhy ${ }^{76}$ are indicated by the dashed lines.

Ota and colleagues ${ }^{45,46,49}$ were probably the first to deliberately use wood as a biomorphic template to produce cellular ceramics. By impregnating the carbon preforms with alkoxide solutions and applying standard sol-gel chemistry, various metal oxide macroporous ceramics have been produced using this approach. SiC-based cellular ceramics of diverse compositions were fabricated by Greil and colleagues ${ }^{52,55-57}$ via the infiltration and reaction of liquid or gaseous silicon metal with the carbon preform. Other gaseous metals and metal precursors, ${ }^{58-60}$ preceramic polymers, ${ }^{63}$ ceramic suspensions, ${ }^{62}$ and salt solutions ${ }^{64,65}$ have recently been employed to infiltrate the

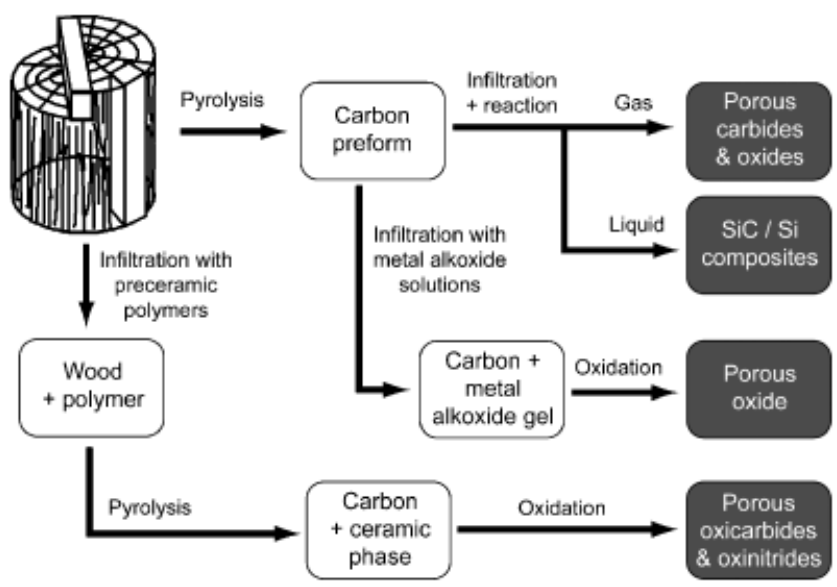

Fig. 5. Processing routes to transform cellular wood structures into macroporous ceramics (adapted from Greil ${ }^{79}$ ). carbon cellular structure and obtain oxide, carbide, phosphate, and zeolite-containing macroporous ceramics through the wood-derived replica technique.

The pore size distribution of wood-derived porous ceramics is determined by the microstructure of the original wood template used. As wood structures may exhibit cell sizes down to a few micrometers, porous ceramics obtained from wood templates display pore sizes markedly lower than those achieved with the polymer replica technique, typically within the range 10-300 $\mu \mathrm{m}$ (Fig. 2). The porosity of these structures is predominantly open and can vary from $25 \%$ up to $95 \%$ depending on the amount of material impregnated into the template, as illustrated in Fig. 2.

The anisotropic nature of cellular ceramics produced using wood as template might be very advantageous in applications that require open and highly oriented porous structures, such as in catalysis and in the filtration of liquids and hot gases. ${ }^{79}$ As a result of their highly oriented structures, the mechanical properties of wood-derived ceramics are markedly anisotropic. The mechanical strength in the axial direction (along the oriented pores) is considerably higher than that in the tangential/perpendicular direction, as indicated in Fig. 4. As in the case of the sponge replica method, the walls of the wood-derived structures might contain flaws/pores generated from the pyrolysis of residual carbon in oxidizing environments. Such pores degrade the mechanical strength of the cellular structure, particularly at high porosity levels (Fig. 4). ${ }^{62,80}$ Structures with high mechanical strength can only be achieved when the carbon preform is totally converted into the ceramic phase. ${ }^{58}$ Another disadvantage of the wood-replica approach is the several time-consuming steps involved (Fig. 5), which might add considerable costs to the process. 
Table II. Examples of Sacrificial Template Methods Reported in the Literature

\begin{tabular}{|c|c|}
\hline Sacrificial template & Compositions \\
\hline $\begin{array}{l}\text { Synthetic organics } \\
\text { PVC beads } \\
\text { PS beads } \\
\text { PEO }^{91} \text { or } \text { PVB }^{99} \text { beads } \\
\text { PMMA }^{87,91,100-105} \text { or PMMA-PEG beads } \\
\\
\text { Phenolic resin } \\
\text { Nylon } \\
\text { Cellulose acetate } \\
\text { Polymeric gels } \\
\text { Naphtalene }\end{array}$ & 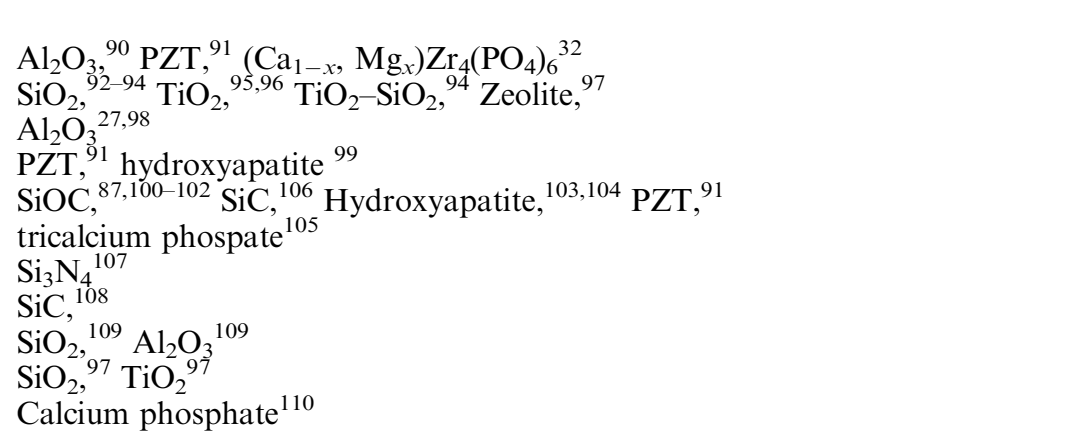 \\
\hline $\begin{array}{l}\text { Natural organics } \\
\text { Gelatine } \\
\text { Peas and seeds } \\
\text { Cellulose/cotton } \\
\text { Glucide } \\
\text { Sucrose } \\
\text { Dextrin } \\
\text { Wax } \\
\text { Alginate } \\
\text { Starch }\end{array}$ & 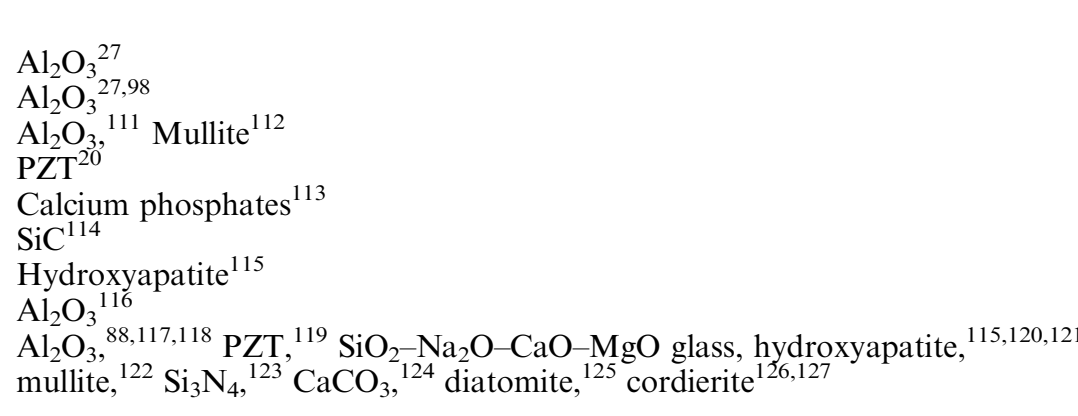 \\
\hline $\begin{array}{l}\text { Liquids } \\
\text { Freeze-drying } \\
\text { Camphene } \\
\text { Water } \\
\text { Emulsions_-Oils }\end{array}$ & $\begin{array}{l}\mathrm{Al}_{2} \mathrm{O}_{3}{ }^{128} \\
\mathrm{Al}_{2} \mathrm{O}_{3},{ }^{129,130} \mathrm{SiO}_{2},{ }^{11,131} \mathrm{Si}_{3} \mathrm{~N}_{4},{ }^{132} \mathrm{Al}_{2} \mathrm{O}_{3}-\mathrm{SiO}_{2}{ }^{133} \\
\mathrm{TiO}_{2},{ }^{134,135} \mathrm{Al}_{2} \mathrm{O}_{3},{ }^{136} \mathrm{Hydroxyapatite}^{137} \mathrm{SiO}_{2},{ }^{138} \mathrm{CaCO}_{3},{ }^{139} \mathrm{FeOOH},{ }^{139} \\
\mathrm{CoOOH},{ }^{139} \mathrm{Mn}_{7} \mathrm{O}_{13} \cdot 5 \mathrm{H}_{2} \mathrm{O}^{133}\end{array}$ \\
\hline $\begin{array}{l}\text { Salts } \\
\qquad \mathrm{NaCl} \\
\mathrm{BaSO}_{4} \text { and } \mathrm{SrSO}_{4} \\
\mathrm{~K}_{2} \mathrm{SO}_{4}\end{array}$ & $\begin{array}{l}\mathrm{SiC}^{89} \\
\mathrm{Al}_{2} \mathrm{O}_{3}{ }^{140} \\
\mathrm{PbTiO}_{3}, \mathrm{La}_{1-x} \mathrm{Sr}_{x} \mathrm{MnO}_{3}{ }^{141}\end{array}$ \\
\hline $\begin{array}{l}\text { Metals/ceramics } \\
\text { Nickel } \\
\text { Carbon (graphite, fiber, nanotubes) } \\
\mathrm{SiO}_{2} \text { (particles, fibers) } \\
\mathrm{ZnO}\end{array}$ & $\begin{array}{l}\mathrm{YSZ}_{,}^{142} \mathrm{Al}_{2} \mathrm{O}_{3}{ }^{142} \\
\mathrm{SiC}^{108} \text { mullite }^{144} \\
\mathrm{SiC}^{108} \\
\mathrm{NiO}^{145}\end{array}$ \\
\hline
\end{tabular}

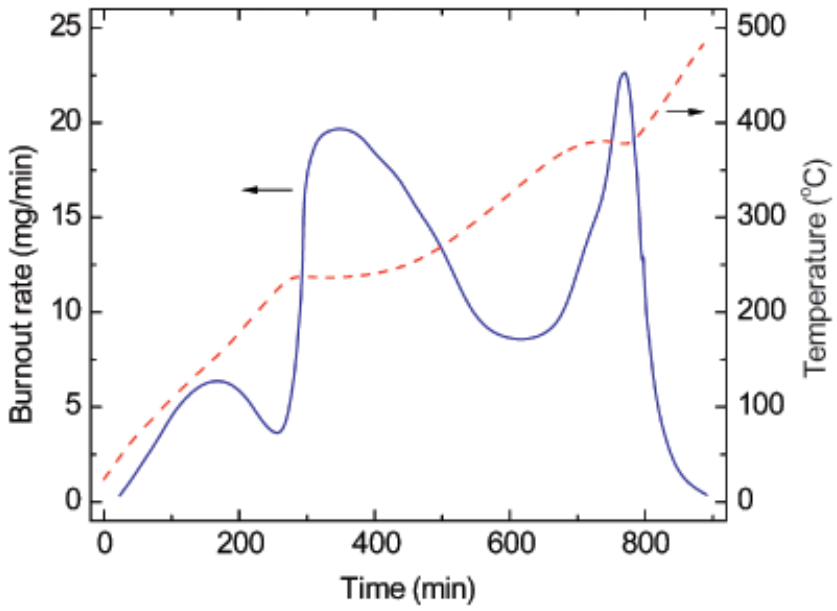

Fig. 6. Typical heat treatment applied for the pyrolysis of organic sacrificial phases. In this case, the starch used as organic template is removed in two steps at about $250^{\circ}$ and $370^{\circ} \mathrm{C}$ (data from Lyckfeldt and Ferreira ${ }^{88}$ ).
Numerous other approaches using synthetic ${ }^{81}$ or natural biomorphic templates such as plants, ${ }^{82,83}$ egg shell membrane, ${ }^{84,85}$ bacteria, ${ }^{11}$ and bioclastic structures formed by aquatic organisms (e.g., diatoms) ${ }^{86}$ have also been applied in the last years to fabricate meso- and macroporous particles, films and unique $3 \mathrm{D}$ porous structures up to $100 \mu \mathrm{m}$ in size. Although a detailed description of these porous materials go beyond the scope of this article, the references cited above might be useful for the interested reader.

\section{Sacrificial Template Method}

The sacrificial template technique usually consists of the preparation of a biphasic composite comprising a continuous matrix of ceramic particles or ceramic precursors and a dispersed sacrificial phase that is initially homogeneously distributed throughout the matrix and is ultimately extracted to generate pores within the microstructure (Fig. 1(b)). This method leads to porous materials displaying a negative replica of the original sacrificial template, as opposed to the positive morphology obtained from the replica technique described above. 

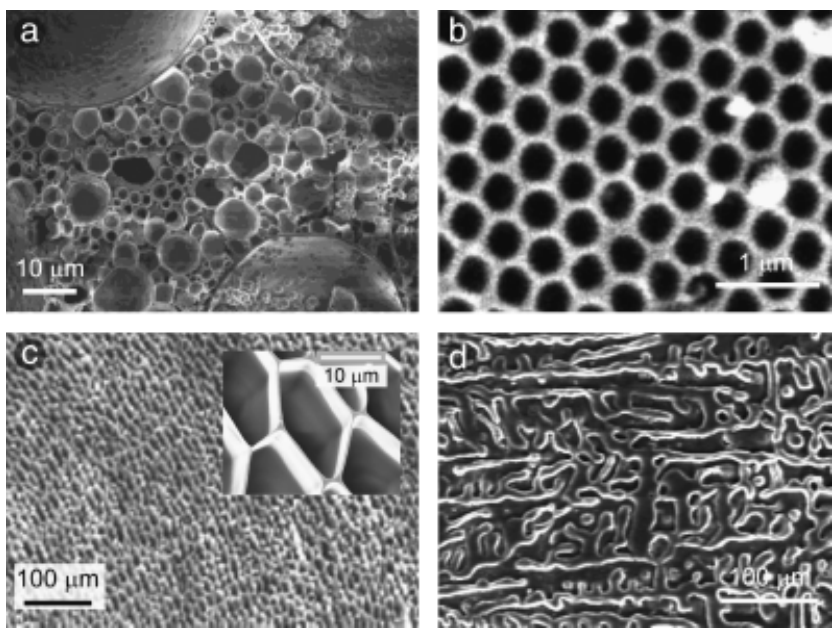

Fig. 7. Microstructures of macroporous ceramics produced with the sacrificial template method. (a) $\mathrm{TiO}_{2}$ foam exhibiting hierarchical porous structure produced via emulsion templating, ${ }^{135}$ (b) ordered macroporous $\mathrm{SiO}_{2}$ obtained using polystyrene beads as templates, ${ }^{92}$ (c) highly oriented $\mathrm{SiO}_{2}$ honeycomb structure achieved via the unidirectional freeze-drying of silica gels, ${ }^{131}$ (d) macroporous $\mathrm{Al}_{2} \mathrm{O}_{3}$ exhibiting dendrimer-like pores obtained using camphene as sacrificial template. ${ }^{128}$

The biphasic composite is commonly prepared by (a) pressing a powder mixture of the two components, ${ }^{87}$ (b) forming a twophase suspension that is subsequently processed by wet colloidal routes such as slip, tape or direct casting, ${ }^{88}$ or (c) impregnating previously consolidated preforms of the sacrificial material with a preceramic polymer or ceramic suspension. ${ }^{89}$

The way that the sacrificial material is extracted from the consolidated composite depends primarily on the type of pore former employed. A wide variety of sacrificial materials have been used as pore formers, including natural and synthetic organics, salts, liquids, metals, and ceramic compounds. Table II illustrates some examples from the recent literature of possible sacrificial templates.

Synthetic and natural organics are often extracted through pyrolysis by applying long thermal treatments at temperatures between $200^{\circ}$ and $600^{\circ} \mathrm{C} .^{87,92,110}$ The long periods required for complete pyrolysis of the organic component and the extensive amount of gaseous by-products generated during this process are the main disadvantages of using organic materials as sacrificial phase. Figure 6 shows a typical heat treatment employed for removing the organic material. Lyckfeldt and Ferreira $^{88}$ reported that the burnout rate has to be limited to only $20 \mathrm{mg} / \mathrm{min}$ in order to avoid cracking of relatively thin ceramic plates $(3-4 \mathrm{~cm})$ during pyrolysis. Under the conservative assumption that this burnout rate would also hold for larger components, the removal of the sacrificial material from an alumina brick of $5 \mathrm{~cm} \times 10 \mathrm{~cm} \times 23 \mathrm{~cm}$ with aimed porosity of $50 \%$ would require a heat treatment of more than 3 weeks. The mismatch in thermal expansion coefficient between the organic and inorganic phases can also induce cracks within the porous structure during pyrolysis.

Most of these drawbacks can be partially overcome by applying liquid pore formers such as water and oils or a solid phase that can be easily sublimated (e.g., naphtalene) (Table II). Even though the extraction process is also time consuming, liquids and volatile oils can be evaporated or sublimated at milder conditions without generating undesired toxic gases and excessive stresses during removal of the pore former. ${ }^{129-134,136}$

Sacrificial materials such as salts, ceramic and metallic particles, on the other hand, are usually extracted by chemical rather than thermal means. The extraction of salts has been easily accomplished by repeatedly washing the composite with water. ${ }^{89,141}$ Ceramic and metallic particles or fibers require more aggressive agents and are in most cases removed by acidic leaching. ${ }^{108,142,143}$
In all of these processes, the continuous matrix phase has to be partially consolidated before removal of the sacrificial material, so that the porous structure does not collapse during the extraction step. When the continuous phase is a suspension of colloidal ceramic particles, consolidation is usually achieved with the help of setting agents and binders ${ }^{146}$ or through the formation of a stiff attractive network of particles throughout the matrix. ${ }^{88,109,136}$ Alternatively, sol-gel transitions based on the condensation of metal alkoxide and hydroxides in solution has also been used to consolidate the continuous phase. ${ }^{93,134,135}$ In the case of preceramic polymers, consolidation is achieved by cross-linking the macromolecules through a curing process that takes place at temperatures slightly lower than that used for the pyrolysis step. ${ }^{87,89,100,147}$

The use of relatively volatile oils as a sacrificial phase in aqueous ${ }^{135,137,138}$ or non-aqueous ${ }^{134}$ emulsions is an interesting alternative for the fabrication of porous ceramics by this template method. The main advantages of this approach are (a) the fact that the template is easily incorporated into the continuous phase by simple agitation or mixing, (b) the very small droplet/pore sizes that can be achieved when using immiscible liquids exhibiting low interfacial energy, and (c) the mild conditions required for removal of the template.

The emulsion template method has been recently applied in combination with sol-gel reactants and surfactants to fabricate ordered macroporous structures from monodisperse oil droplets obtained by fractionation. ${ }^{134}$ Materials with porosity up to $90 \%$ have also been produced from aqueous emulsions using surface modified particles to stabilize the droplet oil-water interface. ${ }^{136,138}$ The incorporation of a third phase into the emulsions, as for example water in non-aqueous systems and air in aqueous emulsions, has allowed for the fabrication of porous ceramics with a well-defined hierarchical pore size distribution (Fig. 7(a)). ${ }^{135,136}$

The sacrificial template technique is quite flexible with respect to the possible chemical compositions that can be used in the fabrication process. As indicated in Table II, porous ceramics of various chemical compositions have been produced using this approach. A wide number of different oxides have been used to fabricate porous ceramics using starch particles as sacrificial template. The main advantages of this approach are its simplicity, the ready availability of starch particles of various morphologies and sizes $(2-100 \mu \mathrm{m})$, and the fact that it can be applied to any material which can be dispersed in an aqueous suspension. ${ }^{88,120}$ Non-oxide porous ceramics, on the other hand, have been often produced using preceramic polymers in combination with various different template materials (Table II).

One of the main advantages of the sacrificial template method in comparison with the other fabrication routes is the possibility to deliberately tailor the porosity, pore size distribution, and pore morphology of the final ceramic component through the appropriate choice of the sacrificial material. Figure 2 shows that the range of porosity and pore sizes that can be achieved with this technique is very broad $(20 \%-90 \%$ and $1-700 \mu \mathrm{m}$, respectively), as they only depend on the volume fraction and size of the sacrificial template used. Porous materials exhibiting monomodal pore size distribution at various porosity levels can for instance be easily produced using different initial amounts of monodisperse templating particles (Fig. 7(b)).

Porous ceramics with long anisotropic pores and channels have been produced with this method by orienting nickel wires in a magnetic field, ${ }^{143}$ by aligning ceramic-coated cotton threads ${ }^{111}$ or by casting a ceramic suspension into a sacrificial mold displaying long and thin $(0.5 \mathrm{~mm})$ polymeric rods. ${ }^{146}$ Pores with special morphologies have also been produced by a freeze casting approach using water or a high-melting point oil as sacrificial material. By tuning the growth of ice/oil crystals during the unidirectional freezing of suspensions, dendritic or highly oriented porous structures has been obtained after sublimation of the templating crystals (Fig. 7(c)). ${ }^{128-133}$

Since in this method the ceramic component corresponds to the negative of the original template, the removal of the sacri- 


\section{Panel A: Foam Stability}

Liquid foams are thermodynamically unstable systems due to their high gas-liquid interfacial area. Several physical processes take place in wet foams to decrease the overall system free energy, leading to foam destabilization. The main destabilization mechanisms are drainage (creaming), coalescence (film rupture), and Ostwald ripening (disproportionation).

Drainage is the physical separation between the gaseous and liquid phases of the foam because of the effect of gravity. In draining foams, light gas bubbles move upwards forming a denser foam layer on the top, while the heavier liquid phase is concentrated on the bottom, as illustrated in Fig. A1. Bubbles accumulated on the top usually rearrange and deform to form highly packed foams with polyhedral cells. The resulting foam exhibits a three dimensional microstructure characterized by thin films (or lamellas) between the faces of touching cells and so-called Plateau borders at the intersection of three neighboring thin films (Fig. A1).

Coalescence takes place when the thin films formed after drainage are not stable enough to keep the touching cells apart, resulting in the association of neighboring bubbles. The stability of the thin films is determined by the attractive and repulsive interactions between bubbles, as schematically illustrated in Fig. A2. van der Waals attractive forces tend to push the bubbles against each other (negative disjoining pressure) and are thus the main driving force for thin-film collapse. Coalescence can only be hindered by providing electrostatic and/or steric repulsive forces sufficiently strong to overcome the attractive van der Waals forces (Fig. A2(b)). This can be imparted by surfactant molecules or particles attached to the air-water interface (see Panel B).

Foams can be tailored to efficiently prevent drainage and coalescence processes, but seldom can they resist long-term Ostwald ripening or disproportionation. This destabilization mechanism is driven by the difference in Laplace pressure between bubbles of different sizes. The Laplace pressure inside a gas bubble arises from the curvature of the air-water interface. For spherical bubbles of radius $R$ and gas-liquid interfacial energy $\gamma$, the Laplace pressure $\Delta P$ is given by $2 \gamma /$ R. $^{148}$ The difference in Laplace pressure between bubbles of distinct sizes $(R)$ leads to bubble disproportionation and Ostwald ripening because of the steady diffusion of gas molecules from smaller to larger bubbles over time, as indicated in Fig. 10(a). Surfactant and biomolecules adsorbed at the gas-liquid interface can slow down this coarsening process by decreasing the interfacial energy $\gamma$.

The combined action of all these physical processes may collapse the foam within a few seconds after air incorporation. The foam lifetime can be increased to a few minutes or several hours by adsorbing long-chain surfactants or proteins at the air-water interface. ${ }^{149}$ Remarkably stable foams exhibiting lifetime of several days and weeks have been recently prepared through the adsorption of colloidal particles on the surface of air bubbles (see Panel B). ${ }^{150-153}$
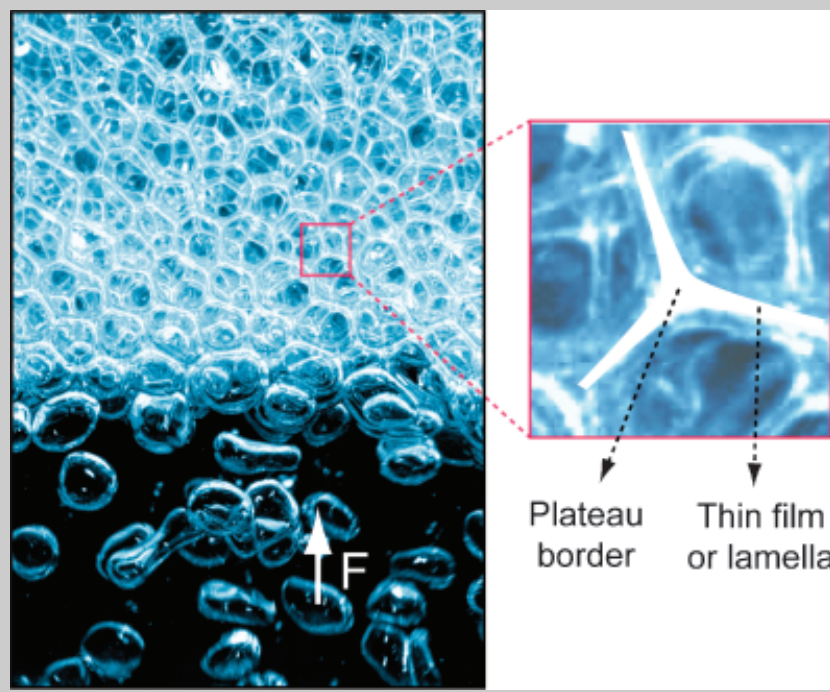

Plateau border Thin film or lamella

Fig. A1. Foam drainage. The Plateau border and thin films formed after bubble rearrangement and distortion on the top foam layer are indicated in the magnified image (adapted from original picture after J.J. Cillier).

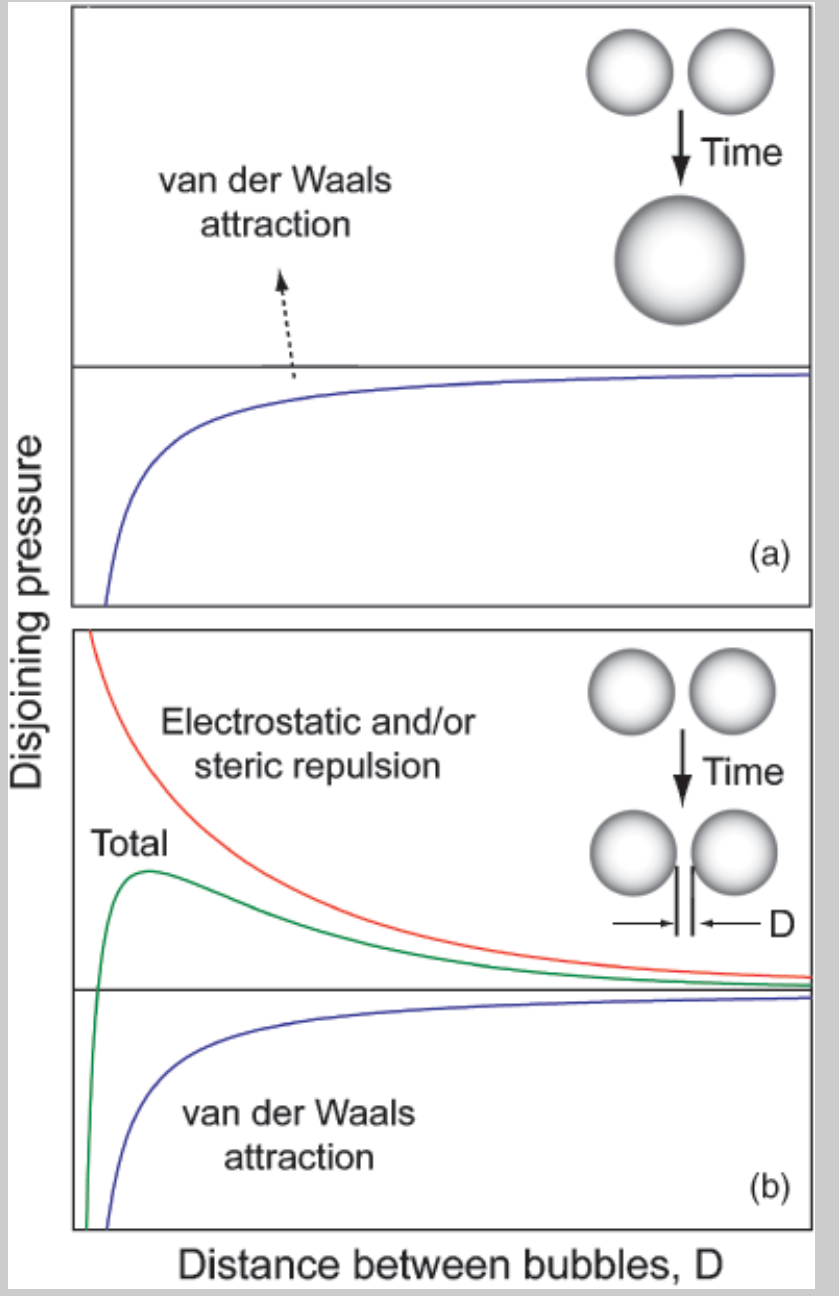

Fig. A2. Schematic dependence of the disjoining pressure among two interacting gas bubbles as a function of their distance $D$. Coalescence is favored by attractive van der Waals forces (a) and can only be hindered by providing steric and/or electrostatic repulsion among the interacting bubbles (b). 


\section{Panel B: Particles at Interfaces}

Colloidal particles have been used to stabilize high energy interfaces for more than a century in so-called Pickering emulsions. ${ }^{154}$ This concept has also been applied for many decades in flotation technology ${ }^{155}$ and has been recently exploited for the preparation of ultra-stable wet foams. ${ }^{150-153}$

The attachment of particles at gas-liquid interfaces occurs when particles are not completely wetted in the liquid phase or, in other words, are partially lyophobic (hydrophobic if the liquid is water). Under this condition, it is energetically favorable to replace part of the high energy solid-liquid area by a solid-gas area through particle attachment at the gas-liquid interface (Fig. B1). The position of the particles at the interface is ultimately determined by a balance between the gas-liquid, gassolid, and solid-liquid interfacial tensions, as depicted in Fig. B1. A simple way to describe the particle position at the interface is through the contact angle formed at equilibrium through the liquid phase (Fig. B1). Slightly lyophobic particles remain predominantly in the liquid phase and exhibit a contact angle $<90^{\circ}$, whereas extensively lyophobic particles are positioned primarily in the gaseous phase and display a contact angle $>90^{\circ}$.

Similar to the hydrophile-lypophile balance (HLB) used for surfactants, the contact angle of particles determines the dispersed and continuous phases of the mixture. ${ }^{156}$ For equal amounts of gas and liquid (1:1 mixtures), contact angles $<90^{\circ}$ lead to the formation of air in water mixtures (foams), while contact angles $>90^{\circ}$ result in the formation of water in air mixtures (mists), as illustrated in Fig. B1.

Particles attached to the gas-liquid interfaces of foams and mists lower the overall system free energy by replacing part of the gasliquid interfacial area rather than reducing the interfacial tension as in the case of surfactants. ${ }^{156}$ The energy of attachment or free energy gained $(G)$ by the adsorption of a particle of radius $r$ at the interface can thus be calculated using simple geometrical arguments, which lead to the following equations ${ }^{156}$ :

$$
\begin{aligned}
& G=\pi r^{2} \gamma_{L G}(1-\cos \theta)^{2} \text { for } \theta<90^{\circ}, \\
& \text { and } G=\pi r^{2} \gamma_{L G}(1+\cos \theta)^{2} \text { for } \theta>90^{\circ},
\end{aligned}
$$

where $\theta$ is the contact angle and $\gamma_{\mathrm{LG}}$ is the gas-liquid interfacial tension.

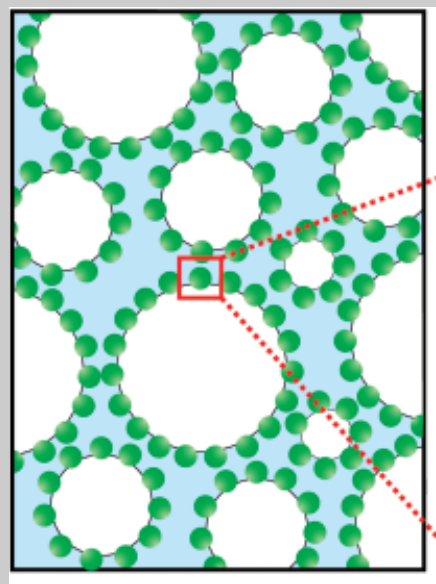

\section{Foams}
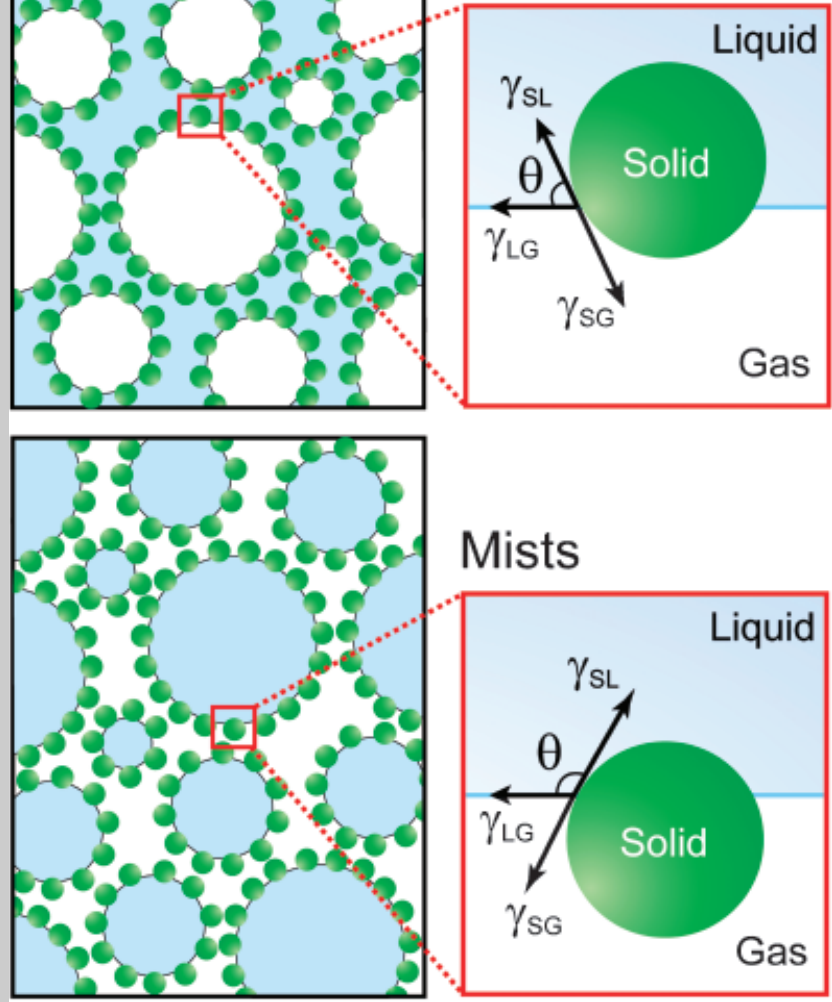

\section{Mists}

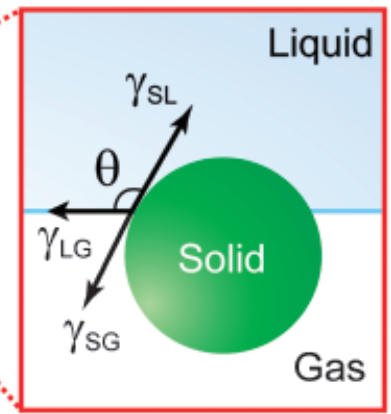

Fig. B1. Scheme of foams and mists that can be produced through the adsorption of colloidal particles at the gas-liquid interface. The drawings on the right hand side indicate the force balance at equilibrium for particles lyophobized to different extents.

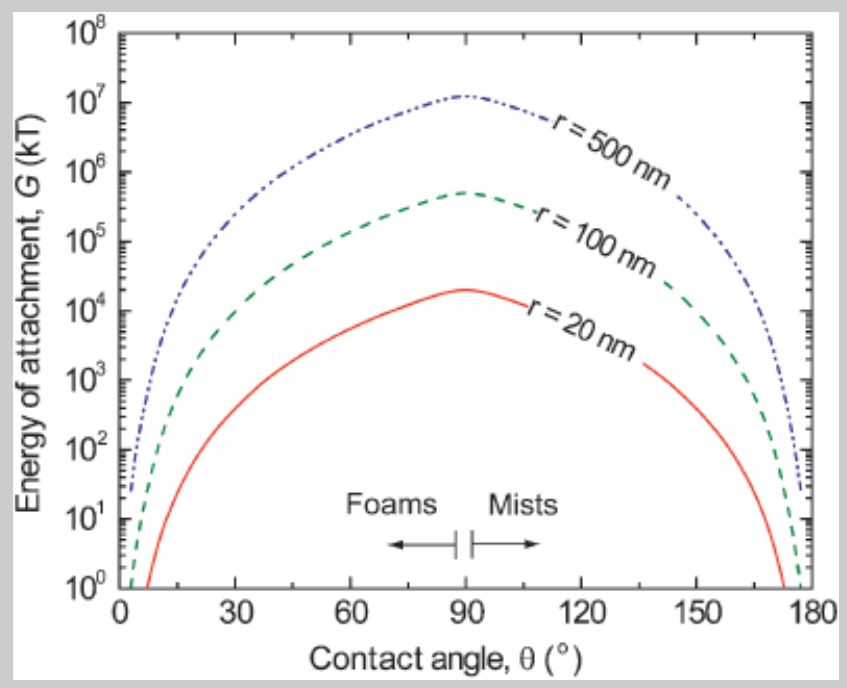

Fig. B2. Energy of attachment of colloidal particles at an air-water interface $\left(\gamma_{\mathrm{LG}}=72.8 \mathrm{mN} / \mathrm{m}\right)$ as a function of the contact angle for different particle radius.

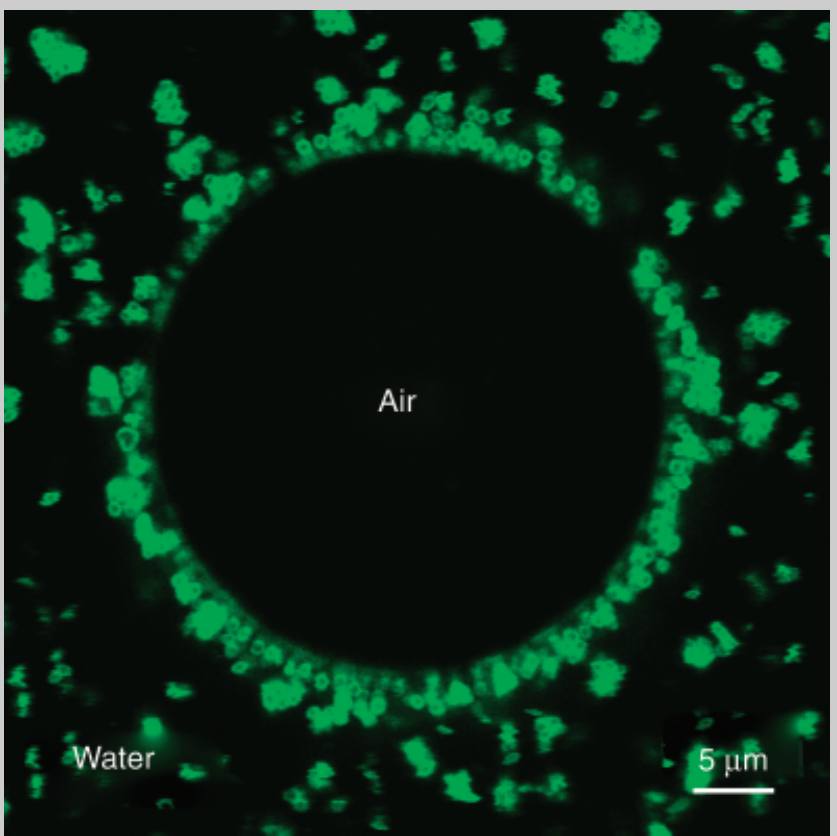

Fig. B3. Confocal microscopy image of fluorescent silica particles adsorbed at an air-water interface after hydrophobization of the particle surface with hexyl amine. ${ }^{153}$ 


\section{Panel B: Continued}

Figure B2 shows the predicted energy of particle attachment $\boldsymbol{G}$ as a function of the contact angle $\theta$ for three different particle sizes. Remarkably, the attachment energy of particles can amount to several thousands or millions of $\boldsymbol{k} \boldsymbol{T} \mathrm{s}$ for contact angles within the range $30^{\circ}<\theta<150^{\circ}$ and particle radius larger than $20 \mathrm{~nm}$ ( $\boldsymbol{k}$ is the Boltzmann constant and $\boldsymbol{T}$ is the temperature). Even though the maximum energy gain is only achieved at $\theta=90^{\circ}$, contact angles as low as $20^{\circ}$ are enough to render attachment energies on the order of $10^{3} \boldsymbol{k} \boldsymbol{T}$ in the case of $100 \mathrm{~nm}$ particles. The surprisingly high energy associated with the adsorption of particles at interfaces contrasts to the extremely lower adsorption energies of surfactants, typically a few $\boldsymbol{k} \boldsymbol{T} \mathrm{s} .{ }^{157}$ For that reason, colloidal particles tend to adsorb irreversibly on interfaces, as opposed to the continuous adsorption and desorption of surfactants. This explains the outstanding stability exhibited by particle-stabilized foams in comparison to surfactant-based systems (Fig. 10). In addition to the steric layer provided against coalescence, particles attached to the air-water interface (Fig. B3) form a network (coating) that strongly hinders the shrinkage and expansion of bubbles, minimizing Ostwald ripening for very long periods of time.

ficial phase does not lead to flaws in the struts as in the case of the positive replica techniques described earlier. Therefore, the mechanical strength of sacrificial-templated porous structures is usually considerably higher than that of porous materials produced via positive replica, as clearly indicated in Fig. 4. Macroporous ceramics obtained with the template method display compressive strengths typically within the range predicted for open and closed-cell structures.

\section{Direct Foaming Methods}

In direct foaming methods, porous materials are produced by incorporating air into a suspension or liquid media, which is subsequently set in order to keep the structure of air bubbles created (Fig. 1(c)). In most cases, the consolidated foams are afterwards sintered at high temperatures to obtain high-strength porous ceramics.

The total porosity of directly foamed ceramics is proportional to the amount of gas incorporated into the suspension or liquid medium during the foaming process. The pore size, on the other hand, is determined by the stability of the wet foam before setting takes place. Wet foams are thermodynamically unstable systems which undergo continuous Ostwald ripening and coalescence processes in order to decrease the foam overall free energy (see Panel A). These destabilization processes significantly increase the size of incorporated bubbles, resulting in large pores in the final cellular microstructure. Therefore, the most critical issue on direct foaming methods is the approach used to stabilize the air bubbles incorporated within the initial suspension or liquid media. We describe below the main direct foaming methods currently available, according to the approach used for foam stabilization.

\section{(1) Stabilization with Surfactants}

Several long-chain amphiphilic molecules and biomolecules such as lipids and proteins can be used as surface-active agents to stabilize wet aqueous foams. These molecules slow down the coalescence and disproportionation of bubbles by adsorbing at the air bubble surface and reducing the air-water interfacial energy. However, due to the low adsorption energy of surfactants at the gas-liquid interface (see Panel B), long-chain surfactants and biomolecules cannot prevent the long-term destabilization of foams. Wet foams stabilized with long-chain surfactants collapse within a few minutes after foaming, whereas those stabilized by proteins exhibit bubble disproportionation within a few hours.

Therefore, direct foaming based on surfactants require a setting agent to consolidate the foam microstructure before extensive coalescence and disproportionation take place. The ultimate pore size of the porous ceramic depends on a balance between the kinetics of bubble disproportionation and the speed of liquid/suspension setting. Small pore sizes $(\sim 50 \mu \mathrm{m})$ can only be achieved by using efficient surfactants and by rapidly setting the wet foam. Table III depicts examples of surfactants used for the stabilization of foams in direct foaming methods.

Numerous processing routes have been developed in the last decades to prepare porous ceramics using direct foaming methods based on surfactants. Several methods have been addressed in previous review articles by Sepulveda ${ }^{68}$ and SaggioWoyansky et $a .^{21}$ Here, we focus mainly on techniques which are flexible in terms of possible chemical compositions and which can be deliberately tuned to control the final porosity, pore morphology, and size distribution. Table IV depicts the main techniques that fulfill these conditions and have been thus extensively investigated in recent years. The fabrication processes differ mainly with respect to the method of air incorporation, foam setting, and possible chemical compositions (Table IV).

Some of these direct foaming methods were adapted from conventional techniques used for the production of polymer foams. Following the success of the polymer replica approach, Wood et al. ${ }^{174}$ patented a process in 1974 where ceramic particles are not used to impregnate already formed polymer

Table III. Examples of Surfactants Used for the Stabilization of Foams in Direct Foaming Methods

Surfactant

\begin{tabular}{|c|c|c|c|c|}
\hline Type & Molecule & Trade name & Supplier & Reference \\
\hline Nonionic & $\begin{array}{l}\text { PEG-8 octyl phenyl ether } \\
\text { PEG-11 nonyl phenyl ether } \\
\text { PEG-11 C10 oxo-alcohol } \\
\text { PEG-20 sorbitan oleate } \\
\text { Cocoalkyldimethylamine oxide } \\
\text { Poly(dimethylsiloxane) copolymer }\end{array}$ & $\begin{array}{l}\text { Triton X-114 } \\
\text { Igepal CO-710 } \\
\text { Lutensol ON110 } \\
\text { Tween } 80 \\
\text { Fongraminox KC-B } \\
\text { Tegostab BF } 2370\end{array}$ & $\begin{array}{l}\text { Fluka } \\
\text { Rhodia } \\
\text { BASF } \\
\text { Fluka } \\
\text { Clariant } \\
\text { Degussa }\end{array}$ & $\begin{array}{l}\text { Sepulveda and Binner }{ }^{158} \\
\text { Santos et al. }{ }^{159} \\
\text { Ortega et al. }{ }^{160} \\
\text { Sepulveda and Binner }{ }^{158} \\
\text { Ortega et al. }{ }^{160} \\
\text { Colombo and Modesti }{ }^{161}\end{array}$ \\
\hline Anionic & Sodium dodecyl sulfate (SDS) & - & Fluka & Fujiu et al., ${ }^{162}$ Tomita et al. ${ }^{163}$ \\
\hline Cationic & Benzethonium chloride & - & Lancaster & Park et al. ${ }^{200}$ \\
\hline Protein & Albumin & - & - & Dhara and Bargava, ${ }^{164}$ Delgado et al. ${ }^{165}$ \\
\hline
\end{tabular}


Table IV. Examples of Direct Foaming Methods Reported in the Literature

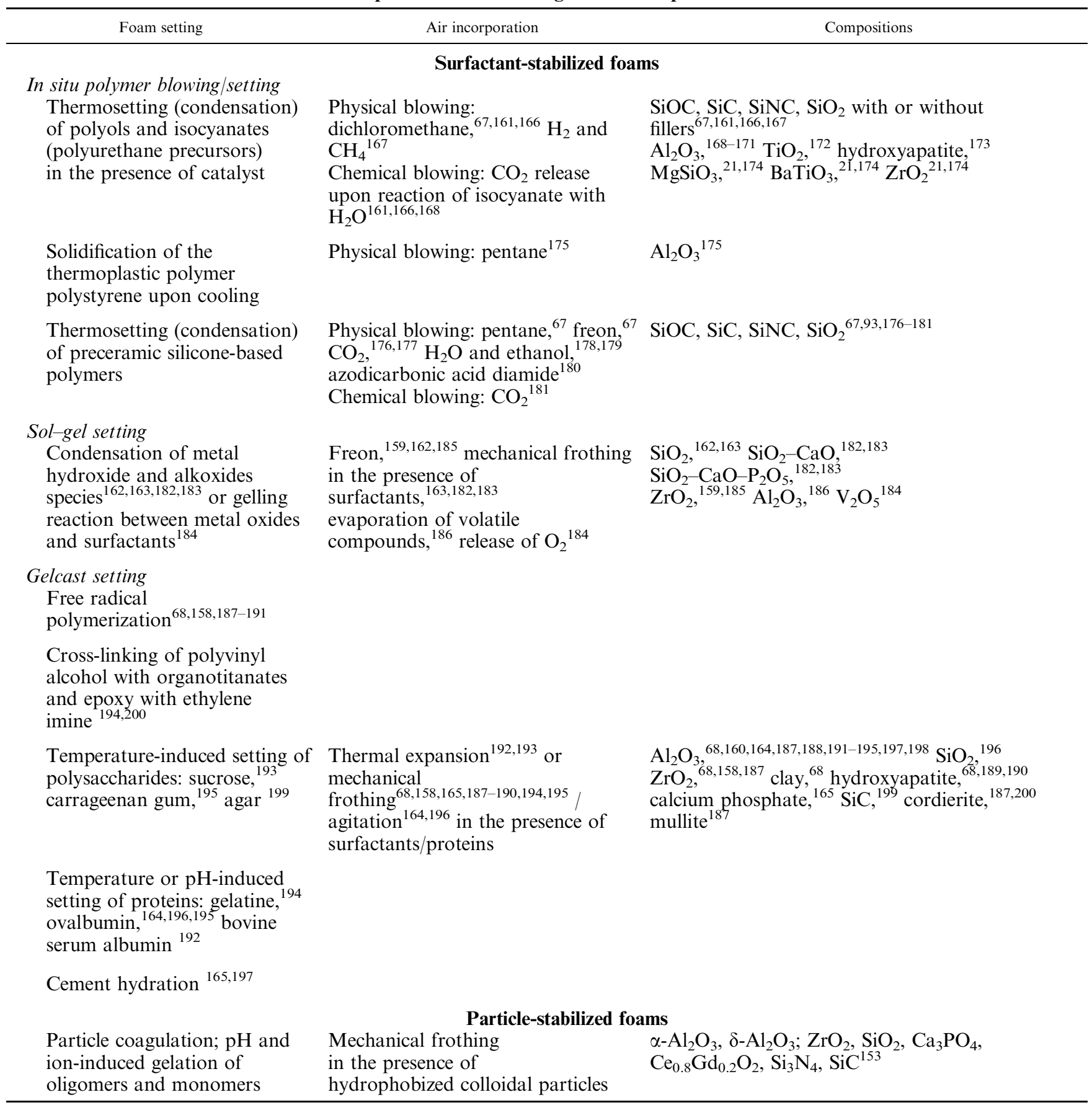

foams, but are instead incorporated into organic solutions containing precursors of a polyurethane foam. The obtained ceramic/organic mixtures are foamed by in situ gas incorporation in the presence of surfactants (Table IV) and finally consolidated by the thermosetting condensation reaction between polyols and polyisocyanates (polyurethane precursors). The in situ incorporation of gas occurs through the nucleation and growth of gas bubbles upon heating (physical blowing) or chemical reaction (chemical blowing) (Table IV). By this method, the ceramic particles are distributed within the polymeric phase, avoiding the formation of hollow struts that usually degrade the foam final mechanical strength after pyrolysis (Fig. 4). ${ }^{169}$ Porous ceramics of various chemical compositions were produced by Minnear, ${ }^{168}$ Evans and co-workers ${ }^{169,170,172}$ using the above mentioned approach (Table IV).

Recently, Colombo et al. ${ }^{67,100,166}$ developed a method where the ceramic particles from Wood's technique are replaced by preceramic silicon based polymers, enabling the production of porous ceramics based on amorphous $\mathrm{SiC}$, SiOC, SiNC compositions of enhanced high temperature properties. Porous ceramics with these compositions have also been produced without polyurethane precursors using solely the thermosetting properties of silicon based polymers in combination with in situ blowing agents, either in the presence of surfactants ${ }^{67}$ or by applying a pressure-drop technique. ${ }^{176}$ The well-established polymer technology used for the production of thermoplastic polystyrene foams was also recently applied by Williams and Evans $^{175}$ to fabricate ceramic foams with up to $84 \%$ porosity, as illustrated in Table IV.

Foam consolidation has not been restricted only to polymeric setting systems, but has been imparted also by inorganic materials exhibiting sol-gel phase transitions in liquid medium. This approach was used by Fujiu et al. ${ }^{162}$ to prepare silica foams using Freon for gas incorporation during the condensation 

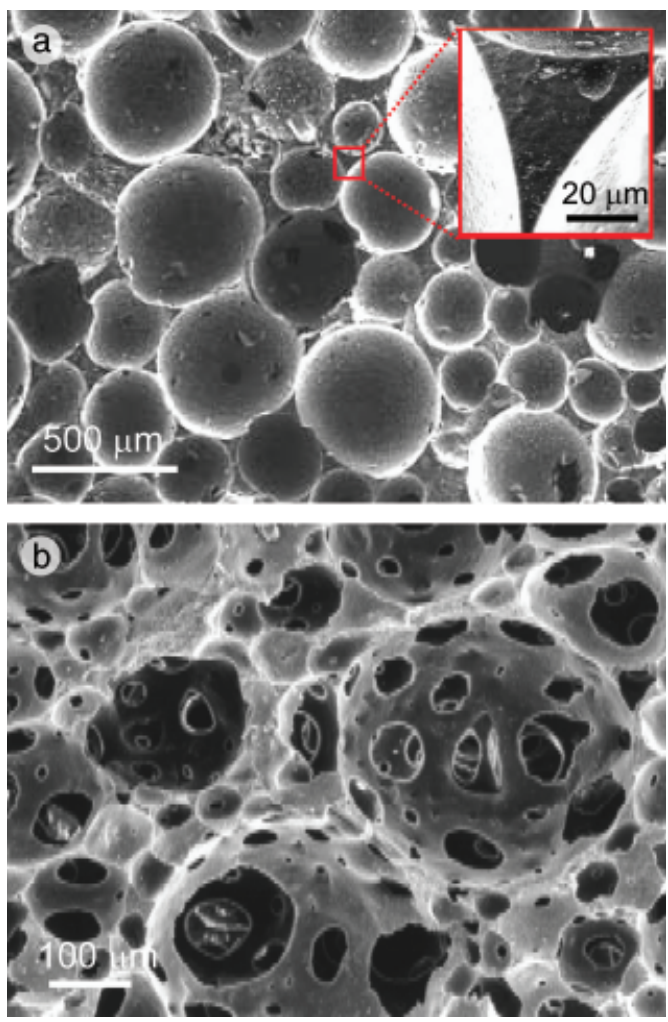

Fig. 8. Microstructures of macroporous ceramics produced by direct foaming with long-chain surfactants as foam stabilizers. ${ }^{66-68}$ (a) shows a closed-cell foam produced from preceramic polymers and polyurethane precursors ${ }^{67}$ highlighting the dense struts typically obtained with direct foaming methods. (b) depicts an open-cell ceramic foam produced through the in situ polymerization of monomers shortly after air incorporation. $^{68}$

reaction of colloidal silica. Tomita et al. ${ }^{163}$ have recently reported a similar method to prepare silica foams, where air is incorporated by mechanical frothing with surfactants in order to avoid the harmful effects of chloroflourocarbons. A sol-gel method using metal alkoxide solutions that lead to biocompatible $\mathrm{SiO}_{2}$-based compositions has also been developed for the production of porous scaffolds for bone replacement and tissue repair. ${ }^{182,183}$ Recently, Santos et al. ${ }^{159,185}$ applied the sol-gel technique to produce $\mathrm{ZrO}_{2}$ porous ceramics from the condensation reaction of zirconium oxychloride in combination with Freon and surfactants. A special sol-gel-based method for the production of $\mathrm{Al}_{2} \mathrm{O}_{3}$ ultralight foams was recently developed by Grader et al. ${ }^{186}$ using metal organic crystals as precursors. Even though the preparation of porous ceramics by sol-gel can in principle be extended to many other chemical compositions, the technique has been predominantly applied to silica-based systems.
In order to produce porous ceramics with a wider chemical compositional range, several techniques using polymeric setting systems instead of the silica-based sol-gel transitions have been developed since the 1990s. The amount of organics applied in these so-called gelcasting methods is, however, significantly lower than that used in previous polymer blowing techniques (Table IV), reducing the need of an extensive pyrolysis step before sintering and allowing for the formation of porous ceramics with controlled degree of pore interconnectivity. ${ }^{68}$

The in situ free radical polymerization of acrylamide monomers, originally developed for dense ceramics, was successfully used for setting ceramic foams of various compositions by Binner and colleagues. ${ }^{158,187}$ The toxicity of the monomers originally used and the need of oxygen-free environments to accomplish the polymerization reaction are the main disadvantages of this method.

The drawbacks of the first gelcasting system were partially ${ }^{188}$ or totally ${ }^{194,200}$ overcome by replacing the original organic additives by less harmful polymerizable monomers ${ }^{188}$ or by applying non-toxic cross-linking reactants which do not require oxygen-free atmosphere. ${ }^{194,200}$ In the last years, several alternative methods that apply environmental-friendly setting agents from the food industry have been developed to circumvent the shortcomings of the original gelcasting technique. The temperature or $\mathrm{pH}$-induced gelation of gelatine, ${ }^{194}$ ovalbumin, ${ }^{164,196,195}$ and bovine serum albumin, ${ }^{192}$ for instance, have been successfully used for setting the foam wet structure. A similar approach relying on the temperature-induced gelling of polysaccharides such as sucrose, ${ }^{193}$ agar, ${ }^{199}$ and carrageenan gum ${ }^{195}$ has been recently applied as non-toxic processing route for the fabrication of porous ceramics. Many of these alternative-setting methods are considerably slower than the original polymerization reaction. Consequently, the speed of the setting reaction is another important criterion, besides toxicity and atmosphere sensitivity, when selecting direct foaming methods for fabrication of porous ceramics of small pore size $(<200 \mu \mathrm{m})$.

By controlling the foam stability and the setting kinetics, pore sizes within the range of $35 \mu \mathrm{m}$ to $1.2 \mathrm{~mm}$ have been achieved using the above surfactant-based direct foaming methods (Fig. 2). Figure 2 also shows that the porosity of cellular structures produced via surfactant-based direct foaming can be tuned from approximately $40 \%$ up to $97 \%$. The pores obtained with this method are typically spherical and can be either closed or opened depending on the foam wet processing (Fig. 8). Open pores exhibiting interconnecting windows (Fig. 8(b)) are obtained if particles segregate at the plateau borders of the foam because of bubble disproportionation (see Panel A). Closed pores, on the other hand, are typically achieved when the particles are distributed uniformly around the gas bubbles upon setting (Fig. 8(a)). These conditions can be controlled in the process by adjusting the foam stability, air content, particle concentration, and setting kinetics.

As opposed to the replica techniques, the direct foaming methods usually lead to dense flawless struts after sinter-

Table V. Typical Conditions Required for the Preparation of Ultra-Stable Particle-Stabilized Foams with Powders of Various Surface Chemistries

\begin{tabular}{|c|c|c|c|c|c|c|c|}
\hline \multicolumn{2}{|c|}{ Particle } & \multicolumn{2}{|c|}{ Amphiphile } & \multirow[b]{2}{*}{ Water $\mathrm{pH}$} & \multirow[b]{2}{*}{ Solids content (vol\%) } & \multirow[b]{2}{*}{ Air content ( $\%$ air $)$} & \multirow[b]{2}{*}{ Mean bubble size $(\mu \mathrm{m})$} \\
\hline Type & Size, d50 (nm) & Type & Conc. $(\mathrm{mol} / \mathrm{L})$ & & & & \\
\hline \multicolumn{8}{|l|}{ High IEP } \\
\hline$\alpha-\mathrm{Al}_{2} \mathrm{O}_{3}$ & 200 & Valeric acid & 0.030 & 4.75 & 35 & 80 & 26 \\
\hline \multicolumn{8}{|c|}{ Intermediate IEP } \\
\hline $\mathrm{ZrO}_{2}$ & 50 & Propyl gallate & 0.080 & 9.9 & 22 & 79 & 70 \\
\hline $\mathrm{Ca}_{3}\left(\mathrm{PO}_{4}\right)_{2}$ & 50 & Butyl gallate & 0.040 & 9.9 & 17 & 86 & 45 \\
\hline \multicolumn{8}{|l|}{ Low IEP } \\
\hline $\mathrm{SiO}_{2}$ & 80 & Hexyl amine & 0.065 & 10.6 & 35 & 82 & 30 \\
\hline
\end{tabular}

IEP, Isoelectric point. 


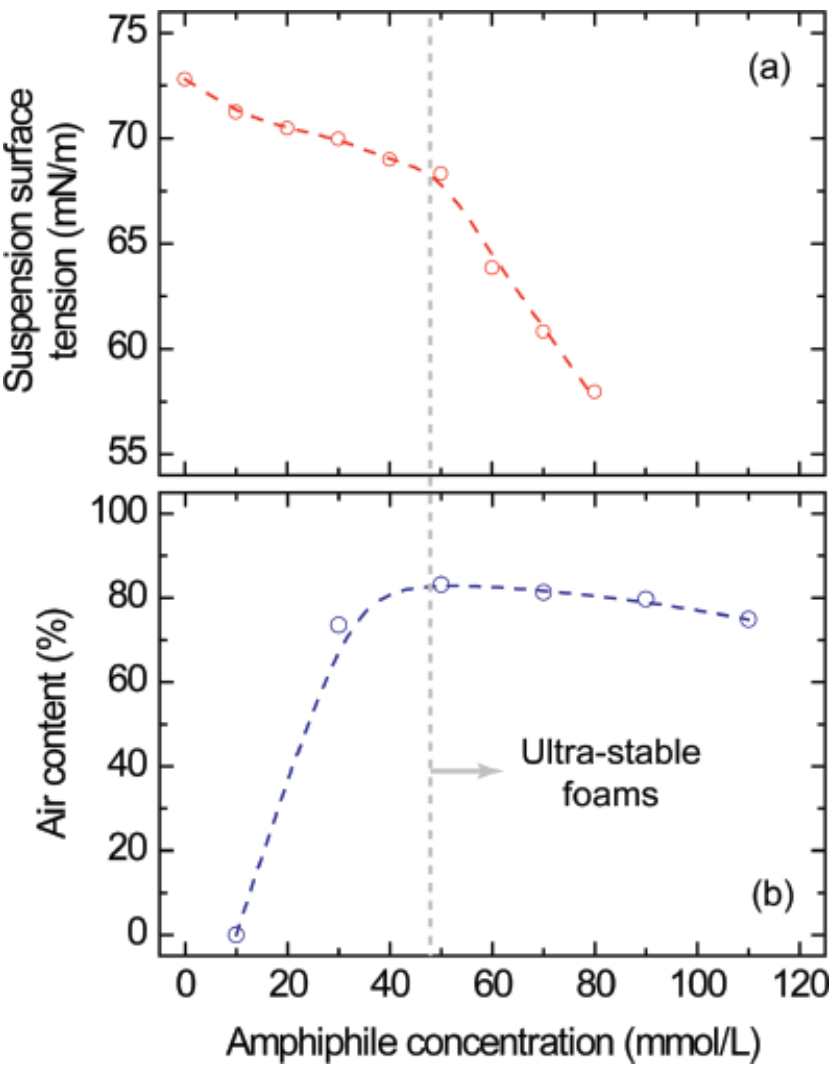

Fig. 9. (a) Surface tension of colloidal suspensions containing different amphiphile concentrations. The abrupt drop in surface tension observed for concentrations higher than $50 \mathrm{mmol} / \mathrm{L}$ (in this case) results from the adsorption of amphiphile-coated particles at the air-water interface. Graph (b) shows the foamability of the colloidal suspensions after mechanical frothing. Ultra-stable foams are obtained when the surface modified particles are hydrophobic enough to attach at the air-water interface. The suspensions described in this example were prepared with $35 \mathrm{vol} \%$ of alumina particles $(200 \mathrm{~nm})$ using butyric acid at $\mathrm{pH} 4.75$ as amphiphile.

ing (Fig. 8(a)), which markedly increase the mechanical strength of the porous ceramic in comparison with the replicaderived structures (Fig. 4). For porosities higher than $90 \%$ (relative density $<10 \%$ ) the cell walls are markedly thin, leading to lower mechanical strength than that theoretically estimated for open-cell structures (Fig. 4). However, by decreasing the porosity (increasing density) pores gradually change from a highly open to a completely closed morphology, increasing the strength towards the level predicted for closed-cell structures.

\section{(2) Stabilization with Particles}

Solid particles with tailored surface chemistry have lately been shown to efficiently stabilize gas bubbles upon adsorption at the air-water interface (see Panel B). ${ }^{150-153}$ Particles adsorbed at the gas-liquid interface were observed to impede the destabilization mechanisms responsible for bubble coalescence and disproportionation for several days, as opposed to the few minutes typically required for the collapse of foams prepared with long-chain surfactants. ${ }^{153}$ Based on this remarkable long-term stability, we developed a direct foaming method that uses colloidal particles as foam stabilizers in order to produce macroporous ceramics with smaller pore sizes than those obtained with surfactant-based foaming techniques. ${ }^{153,201}$

In this method, the attachment of colloidal particles at the air-water interface is promoted by deliberately changing the wettability of the particle upon adsorption of short-chain amphiphilic molecules on the surface. The amphiphiles initially added to the suspension render the particle partially hydropho-
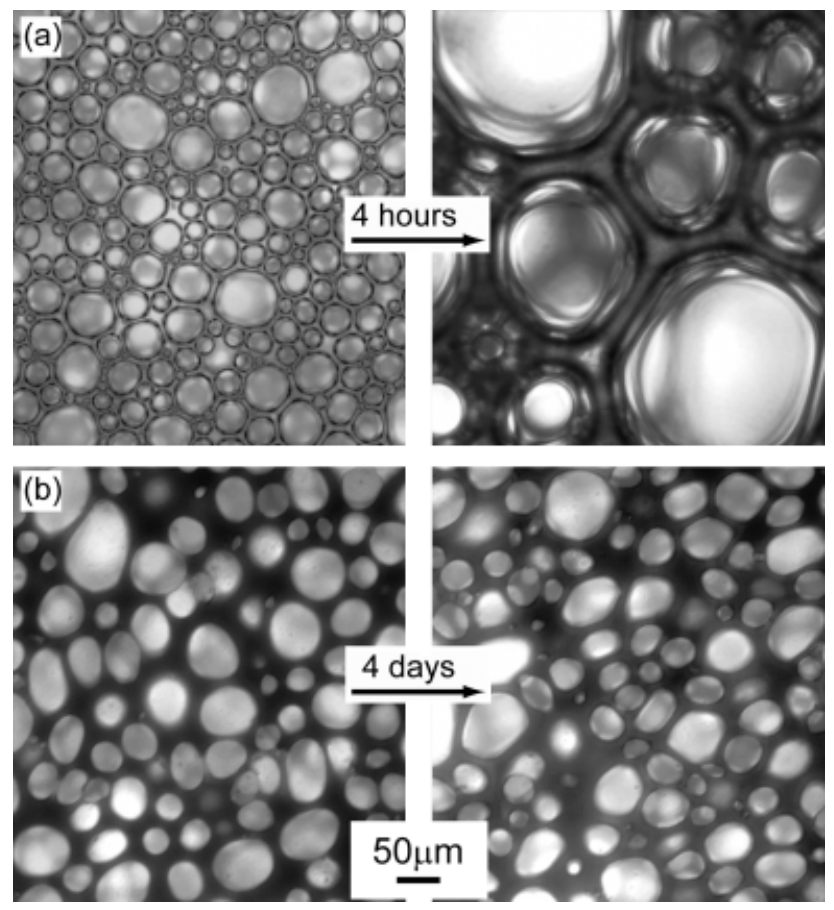

Fig. 10. Stability of particle-stabilized foams (in b) as compared with a well-established shaving foam stabilized with long-chain surfactants (Gillette $^{\mathrm{TM}}$, in a). Significant bubble coalescence and disproportionation occurs in the surfactant-stabilized foam after a few hours from air incorporation, whereas the bubble size of particle-stabilized foams remains unchanged for periods as long as 4 days.

bic by adsorbing with its polar anchoring group on the surface and leaving a short hydrophobic tail (up to six carbons) in contact with the aqueous phase. Table V depicts some of the amphiphilic molecules that can be used for the surface modification of particles displaying various surface chemistries.

A minimum amphiphile concentration is required to impart enough hydrophobicity on the particle surface and induce their attachment at the air-water interface. This is indicated in Fig. 9(a) for the case of submicrometer alumina particles modified with a short-chain fatty acid at $\mathrm{pH} 4.75$. The sudden drop in the suspension surface tension above a critical amphiphile concentration (in this case $\sim 50 \mathrm{mmol} / \mathrm{L}$ ) indicates the adsorption of the surface hydrophobized particles at the airwater interface. Above this critical condition, the particles are able to promptly attach to air bubbles incorporated into the suspension during the direct foaming process. The adsorption of partially hydrophobic particles at an air-water interface after surface modification was confirmed by confocal laser scanning microscopy (see Panel B).

After the surface modification of particles, air can be easily incorporated by mechanical frothing, injection of gas stream, or initiation of a chemical reaction that releases gaseous by-products directly into the initially fluid suspension. Figure 9(b) shows an example of the foamability achieved upon mechanical frothing of a $35 \mathrm{vol} \%$ suspension containing alumina particles partially hydrophobized with the short-chain fatty acid. In this example, air contents up to $80 \mathrm{vol} \%$ were incorporated upon addition of amphiphiles beyond the critical concentration required for particle attachment at the gas-liquid interface. After air incorporation, the partially hydrophobic particles form a slightly coagulated network throughout the aqueous continuous phase, leading to relatively stiff viscoelastic foams with unprecedented long-term stability.

The stability of particle-stabilized foams prepared with this method is compared in Fig. 10 with that of a surfactantstabilized shaving foam known to be extremely resistant against coalescence and Ostwald ripening. The particle-stabilized foam is completely stable against drainage, coalescence and dispro- 

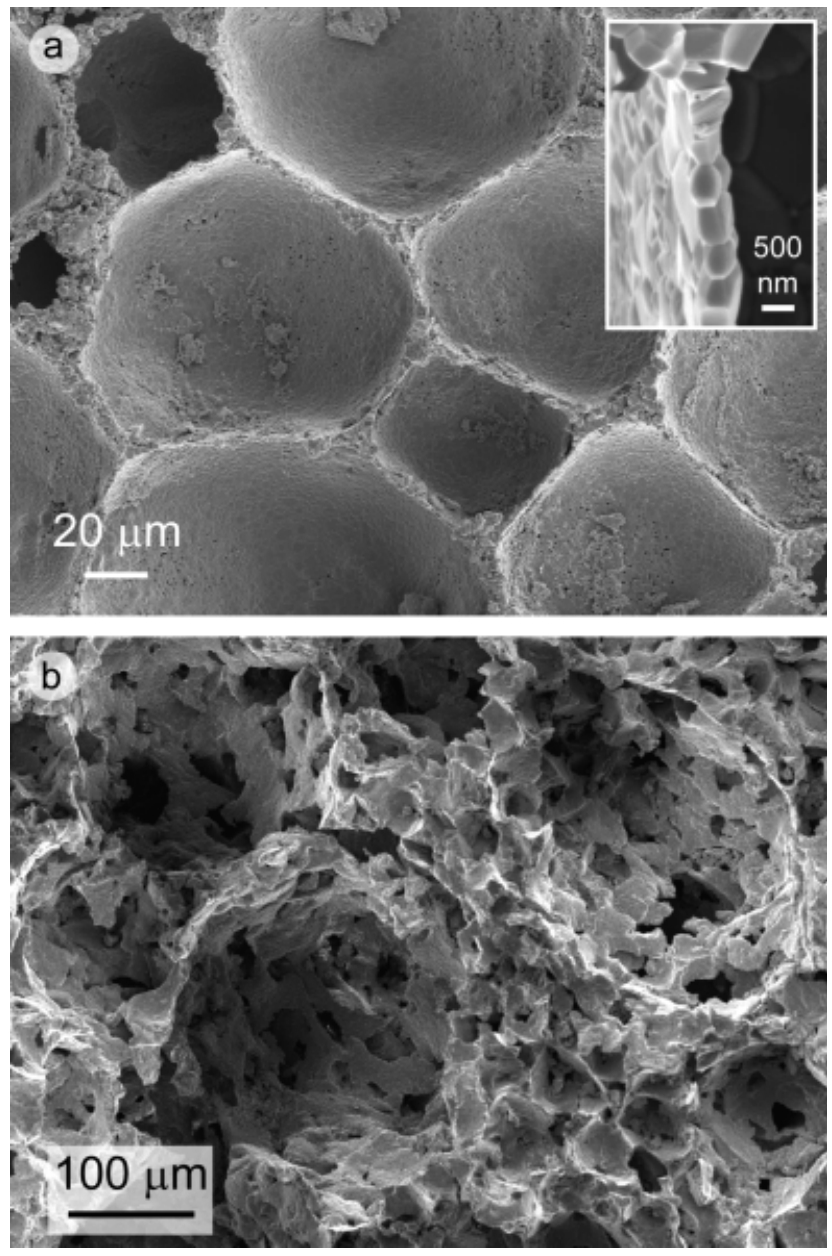

Fig. 11. Microstructures of macroporous ceramics produced by direct foaming with particles as foam stabilizers. (a) Displays a closed-cell foam produced from $35 \mathrm{vol} \%$ suspensions containing alumina particles surface hydrophobized with valeric acid. The inset in (a) shows that the cell wall of these structures can be thinned down to the width of single grains after drying and sintering the wet foams. ${ }^{201}$ (b) Depicts an open-cell ceramic foam produced from $20 \mathrm{vol} \%$ suspensions containing alumina particles surface modified with propyl gallate. In this case, $0.05 \mathrm{wt} \%$ alginate (based on the powder) was used as gelling agent.

portionation for more than 4 days, as opposed to the approximately fourfold increase in average bubble size observed in the shaving foams after only $4 \mathrm{~h}$. The outstanding stability achieved with this novel direct foaming method relies on the irreversible adsorption of colloidal particles at the air-water interface of the gas bubbles, as opposed to the continuous adsorption-desorption experienced by conventional surfactant molecules (see Panel B). ${ }^{150-153}$ Particles irreversibly adsorbed at the interface sterically impede the coalescence of neighboring bubbles and also form a coating layer that restrict bubble shrinkage and expansion in such a way that Ostwald ripening is strongly hindered. $^{153}$

Because of its remarkable stability, particle-stabilized foams do not necessarily require a setting step and can thus be directly dried and sintered to obtain the macroporous ceramic. In the absence of a setting system, particle rearrangement within the foam might still take place during drying, leading to a volumetric shrinkage of approximately $3 \%-5 \%$. In this case, unidirectional drying is recommended in order to allow for the homogeneous shrinkage of the foam. This avoids the formation of pores inside the body because of the shrinkage constraints imparted by the outer dried layer formed at early drying stages. Alternatively, the drying step can be facilitated by using one of the setting agents described in Table IV, which prevent significant particle rearrangement during water evaporation, allowing for faster drying rates. One has to keep in mind however that the gelling agents might adversely affect the foaming behavior, which would require further adjustments in the suspension composition to achieve optimum foaming conditions.

Figure 2 shows that the outstanding stability of particlestabilized foams enables the preparation of porous ceramics with more than $80 \%$ porosity exhibiting pore sizes four- to fivefold smaller than those achieved with surfactant-based foaming methods. The porosity of foams produced with this method vary typically between $40 \%$ and $93 \%$, whereas the average pore sizes can be tuned from approximately 10 to 300 $\mu \mathrm{m}$. As the air bubbles in the wet foam can be completely covered with a layer of surface modified particles, porous ceramics with closed pores can be easily prepared with this method (Fig. 11(a)). Interestingly, the layer of particles originally adsorbed on the air bubble surface leads often to the formation of a single-grain thin cell wall in the final porous structure upon foam drying and sintering, as depicted in Fig. 11(a). Figure 4 shows that macroporous ceramics produced from particle-stabilized foams exhibit remarkable mechanical strength at very high porosity levels $(87 \%-90 \%)$ and small pore sizes (e.g., $30 \mu \mathrm{m})$. This strength level is achieved by tailoring the foaming conditions to produce porous structures with closed cells and flawless walls (Fig. 11). Porous ceramics exhibiting open porosity (Fig. 11(b)) has also been prepared with this technique by simply decreasing the concentration of stabilizing particles or by adding minor amounts $(<1 \mathrm{wt} \%)$ of a sacrificial phase into the initial suspension (e.g., graphite particles).

Using this simple, cheap, and environmentally-friendly method, we have fabricated porous ceramics of various porosity levels and pore size ranges (Fig. 2) with many different chemical compositions (Table IV). It is important to note that many other possibilities and variations of the method can be envisaged and are currently being investigated for the fabrication of porous ceramics with tailored microstructure and chemical composition.

\section{Summary and Outlook}

Several processing routes using replica, sacrificial template, or direct foaming methods are nowadays available for the production of macroporous ceramics. The techniques differ greatly in terms of processing features and final microstructures/properties achieved.

The polymer replica technique is an easy and well-established method to prepare open cellular structures with pore sizes ranging from $200 \mu \mathrm{m}$ to $3 \mathrm{~mm}$ at porosity levels between $40 \%$ and $95 \%$. The rheology of the impregnating suspension and its adhesion on the polymeric sponge are the most crucial steps in this method. Despite the overall simplicity of the technique, the mechanical strength of cellular structures produced with this route can be substantially degraded by the formation of cracked struts during pyrolysis of the polymeric sponge.

A novel replica approach that uses wood structures as positive templates was developed in recent years. Highly oriented open pores ranging from 10 to $300 \mu \mathrm{m}$ can be produced with this method at porosities between $25 \%$ and $95 \%$. The most important processing step in this route is the conversion of the wood-derived carbon preform into a ceramic phase. The availability of templates exhibiting the aimed microstructure is also crucial in this method. The mechanical strength of wood-derived ceramics is highly anisotropic and often suffers from the presence of pores on the cell walls because of incomplete or inefficient conversion. The several steps required to convert the wood structures into the macroporous ceramic might also excessively increase the cost of the process.

Sacrificial templating methods provide a straightforward alternative for the fabrication of macroporous ceramics with porosities and average pore sizes ranging from $20 \%$ to $90 \%$ and $1-700 \mu \mathrm{m}$, respectively. Predominantly open pores of various different morphologies can be produced with this method. The most crucial step in this technique is the removal of the sacrificial 
phase by pyrolysis, evaporation, or sublimation. These processes might involve the release of an excessive amount of gases and have to be carried out at sufficiently slow rates in order to avoid cracking of the cellular structure. The slow removal of the sacrificial phase may considerably increase the processing time in the case of large components. The mechanical strength of cellular structures produced with this method is often substantially higher than that achieved with the positive replica techniques mentioned above.

Direct foaming methods offer an easy, cheap, and fast way to prepare macroporous ceramics with open or closed porosities from $40 \%$ to $97 \%$. The pores produced with this approach result from the direct incorporation of air bubbles into a ceramic suspension, eliminating the need for extensive pyrolysis steps before sintering. The stabilization and setting of the wet foams is the decisive step in direct foaming methods. Foams stabilized with surfactants lead to porous ceramics exhibiting average pore sizes from $35 \mu \mathrm{m}$ to $1.2 \mathrm{~mm}$. The use of surface modified particles to stabilize the wet foam has decreased the lower limit of pore sizes achievable via direct foaming to an average value as low as $10 \mu \mathrm{m}$. Such small pore sizes result from the remarkable long-term stability achieved through the irreversible adsorption of colloidal particles at the air-water interface. Cellular structures prepared by direct foaming usually exhibit mechanical strengths considerably higher than that of replica techniques due mainly to the absence of flaws in the cell struts. Compressive strengths as high as $16 \mathrm{MPa}$ at a porosity level of $87 \%-90 \%$ have been obtained with porous ceramics produced from particle-stabilized wet foams.

Taking into account the decisive influence of the processing method on the material's microstructure and properties, the selection of the processing route for the production of porous ceramics depends primarily on the final properties and application aimed. The well-established technology that uses the polymeric sponge replica method for the production of porous filters for molten metal purification is a suitable example to illustrate the appropriate matching between processing route and final application. In our point of view, future work in this field should be directed towards the investigation of suitable methods for specific target applications, focusing on the deliberate tuning of processing parameters that control the microstructure and properties of the final macroporous ceramic. By addressing specific applications, special demands might arise as for example the production of foams that set at mild temperatures and ambient air conditions, the reduction in the number of processing steps, the use of only biocompatible and not-toxic reagents, the production of porous ceramics that do not require subsequent pyrolysis, calcination, and sintering, and obviously the reduction of costs involved in the process. Many investigations have already been carried out following these directions. By further pursuing this strategy, we expect many novel applications and optimized or alternative processing methods to be developed in the near future.

\section{Acknowledgments}

The authors would like to gratefully acknowledge Prof. Gary Messing for the support, manuscript revision, and fruitful discussions. We also thank Ilke Akartuna for her help on revising the literature.

\section{References}

${ }^{1}$ R. W. Rice, Porosity of Ceramics, pp. 539. Marcel Dekker Inc, New York, 1998

${ }^{2}$ M. Scheffler, and P. Colombo, Cellular Ceramics: Structure, Manufacturing, Properties and Applications. p. 645. Weinheim, Wiley-VCH, 2005.

${ }^{3}$ L. J. Gauckler, M. M. Waeber, C. Conti, and M. Jacobduliere, "Ceramic Foam for Molten-Metal Filtration," J. Metals, 37 [9] 47-50 (1985).

${ }^{4}$ S. Y. Shan, J. F. Yang, J. Q. Gao, W. H. Zhang, Z. H. Jin, R. Janssen, and T. Ohji, "Porous Silicon Nitride Ceramics Prepared by Reduction-Nitridation of Silica," J. Am. Ceram. Soc., 88 [9] 2594-6 (2005).

${ }^{5}$ I. H. Arita, V. M. Castano, and D. S. Wilkinson, "Synthesis and Processing of Hydroxyapatite Ceramic Tapes with Controlled Porosity," J. Mater. Sci.-Mater. Med., 6 [1] 19-23 (1995).
${ }^{6}$ J. Will and L. J. Gauckler, "Ceramic Foams as Current Collector in Solid Oxide Fuel Cells (SOFC): Electrical Conductivity and Mechanical Behaviour"; in Proceedings of the Fifth International Symposium on Solid Oxide Fuel Cells (SOFC$V$ ), Aachen, Germany. Edited by U. Stimming, S. C. Singhal, H. Tagawa, and W. Lehnert. The Electrochemical Society Inc, Pennington, NJ, 1997.

${ }^{7}$ P. Colombo, "Conventional and Novel Processing Methods for Cellular Ceramics," Philos. Trans. Roy. Soc. A, 364, 109-24 (2006).

${ }^{8}$ D. J. Green and P. Colombo, "Cellular Ceramics: Intriguing Structures, Novel Properties, and Innovative Applications," Mater. Res. Soc. Bull., 28 [4] 296-300 (2003).

${ }^{9}$ K. S. W. Sing, D. H. Everett, R. A. W. Haul, L. Moscou, R. A. Pierotti, J. Rouquerol, and T. Siemieniewska, "Reporting Physisorption Data for Gas Solid Systems with Special Reference to the Determination of Surface-Area and Porosity (Recommendations 1984)," Pure Appl. Chem., 57 [4] 603-19 (1985).

${ }^{10}$ J. Fricke and A. Emmerling, "Aerogels," J. Am. Ceram. Soc., 75 [8] 2027-36 (1992)

${ }^{11}$ S. Mann, S. L. Burkett, S. A. Davis, C. E. Fowler, N. H. Mendelson, S. D. Sims, D. Walsh, and N. T. Whilton, "Sol-Gel Synthesis of Organized Matter," Chem. Mater., 9 [11] 2300-10 (1997).

${ }^{12}$ U. Ciesla and F. Schuth, "Ordered Mesoporous Materials," Microporous Mesoporous Mater., 27 [2-3] 131-49 (1999).

${ }^{13}$ J. M. Karp, P. D. Dalton, and M. S. Shoichet, "Scaffolds for Tissue Engineering," Mater. Res. Soc. Bull., 28 [4] 301-6 (2003).

${ }^{14}$ M. Lee, J. C. Y. Dunn, and B. M. Wu, "Scaffold Fabrication by Indirect Three-Dimensional Printing," Biomaterials, 26 [20] 4281-9 (2005).

${ }^{15} \mathrm{~S}$. Michna, W. Wu, and J. A. Lewis, "Concentrated Hydroxyapatite Inks for Direct-Write Assembly of 3-D Periodic Scaffolds," Biomaterials, 26 [28] 5632-9 (2005).

${ }^{16} \mathrm{~K}$. Schwartzwalder and A. V. Somers, Method of Making Porous Ceramic Articles, US Pat. No. 3090094, May 21, 1963.

${ }^{17}$ X. P. Pu, X. J. Liu, F. G. Qiu, and L. P. Huang, "Novel Method to Optimize the Structure of Reticulated Porous Ceramics," J. Am. Ceram. Soc., 87 [7] 1392-4 (2004).

${ }^{18}$ D. D. Brown and D. J. Green, "Investigation of Strut Crack Formation in Open Cell Alumina Ceramics," J. Am. Ceram. Soc., 77 [6] 1467-72 (1994).

${ }^{19}$ X. W. Zhu, D. L. Jiang, S. H. Tan, and Z. Q. Zhang, "Improvement in the Strut Thickness of Reticulated Porous Ceramics," J. Am. Ceram. Soc., 84 [7] 1654 6 (2001).

${ }^{20}$ L. Montanaro, Y. Jorand, G. Fantozzi, and A. Negro, "Ceramic Foams by Powder Processing," J. Eur. Ceram. Soc., 18 [9] 1339-50 (1998).

${ }^{21}$ J. Saggio-Woyansky, C. E. Scott, and W. P. Minnear, "Processing of Porous Ceramics," Am. Ceram. Soc. Bull., 71 [11] 1674-82 (1992).

${ }^{22}$ F. F. Lange and K. T. Miller, "Open-Cell, Low-Density Ceramics Fabricated from Reticulated Polymer Substrates," Adv. Ceram. Mater., 2 [4] 827-31 (1987).

${ }^{23}$ J. M. Tulliani, L. Montanaro, T. J. Bell, and M. V. Swain, "Semiclosed-Cell Mullite foams: Preparation and Macro- and Micromechanical Characterization," J. Am. Ceram. Soc., 82 [4] 961-8 (1999).

${ }^{24}$ H. R. Ramay and M. Q. Zhang, "Preparation of Porous Hydroxyapatite Scaffolds by Combination of the Gel-Casting and Polymer Sponge Methods," Biomaterials, 24 [19] 3293-302 (2003).

${ }^{25}$ J. Luyten, I. Thijs, W. Vandermeulen, S. Mullens, B. Wallaeys, and R. Mortelmans, "Strong Ceramic Foams from Polyurethane Templates," $A d v$. Appl. Ceram., 104 [1] 4-8 (2005).

${ }^{26} \mathrm{~J}$. T. Richardson, Y. Peng, and D. Remue, "Properties of Ceramic Foam Catalyst Supports: Pressure Drop," Appl. Catal. A-General, 204 [1] 1932 (2000).

${ }^{27}$ J. Luyten, S. Mullens, J. Cooymans, A. M. De Wilde, and I. Thijs, "New Processing Techniques of Ceramic Foams," Adv. Eng. Mater., 5 [10] 715-8 (2003).

${ }^{28}$ A. E. M. Paiva, P. Sepulveda, and V. C. Pandolfelli, "Processing and Thermomechanical Evaluation of Fibre-Reinforced Alumina Filters," J. Mater. Sci., 34 [11] 2641-9 (1999).

${ }^{29}$ T. Mizrah, A. Maurer, L. J. Gauckler, and J. P. Gabathuler, "Open-Pore Ceramic Foam as Diesel Particulate Filter"; SAE International Congress and Exposition, Paper 890172. SAE Technical Paper Series, Detroit, MI, 1989.

${ }^{30}$ E. Roncari, C. Galassi, and C. Bassarello, "Mullite Suspensions for Reticulate Ceramic Preparation," J. Am. Ceram. Soc., 83 [12] 2993-8 (2000).

${ }^{31}$ E. Sousa, C. B. Silveira, T. Fey, P. Greil, D. Hotza, and A. P. N. de Oliveira, "LZSA Glass Ceramic Foams Prepared by Replication Process," Adv. Appl. Ceram., 104 [1] 22-9 (2005).

${ }^{32}$ D. M. Liu and J. J. Brown, "Lightweight $\left(\mathrm{Ca}_{1-x}, \mathrm{Mg} x\right) \mathrm{Zr}_{4}\left(\mathrm{Po}_{4}\right)_{6}$ Ceramics," Mater. Chem. Phys., 32 [2] 161-7 (1992).

${ }^{33}$ M. R. Nangrejo, X. Bao, and M. J. Edirisinghe, "Processing of Ceramic Foams from Polymeric Precursor-Alumina Suspensions," Cellular Polymers, 20 [1] 17-35 (2001).

${ }^{34}$ M. R. Nangrejo and M. J. Edirisinghe, "Porosity and Strength of Silicon Carbide Foams Prepared Using Preceramic Polymers," J. Porous Mater., 9 [2] 131-40 (2002).

${ }^{35}$ X. Bao, M. R. Nangrejo, and M. J. Edirisinghe, "Preparation of Silicon Carbide Foams Using Polymeric Precursor Solutions," J. Mater. Sci., 35 [17] 4365-72 (2000).

${ }^{36}$ M. R. Nangrejo, X. Bao, and M. J. Edirisinghe, "The Structure of Ceramic Foams Produced Using Polymeric Precursors," J. Mater. Sci. Lett., 19 [9] 787-9 (2000)

${ }^{37}$ M. R. Nangrejo, X. J. Bao, and M. J. Edirisinghe, "Preparation of Silicon carbide-Silicon Nitride Composite Foams from Pre-Ceramic Polymers," J. Eur. Ceram. Soc., 20 [11] 1777-85 (2000).

${ }^{38}$ A. J. Sherman, R. H. Tuffias, and R. B. Kaplan, "Refractory Ceramic Foams-A Novel, New High-Temperature Structure," Am. Ceram. Soc. Bull., 70 [6] 1025-9 (1991). 
${ }^{39}$ R. A. White, E. W. White, and J. N. Weber, "Replamineform-New Process for Preparing Porous Ceramic, Metal, and Polymer Prosthetic Materials," Science, 176 [4037] 922 (1972).

${ }^{40}$ D. P. Skinner, R. E. Newnham, and L. E. Cross, "Flexible Composite Transducers," Mater. Res. Bull., 13 [6] 599-607 (1978).

${ }^{41}$ D. M. Roy and S. K. Linnehan, "Hydroxyapatite Formed from Coral Skeletal Carbonate by Hydrothermal Exchange," Nature, 247 [5438] 220-2 (1974).

${ }^{42}$ J. Hu, J. J. Russell, B. Ben-Nissan, and R. Vago, "Production and Analysis of Hydroxyapatite from Australian Corals Via Hydrothermal Process," J. Mater. Sci. Lett., 20 [1] 85-7 (2001).

${ }^{43}$ B. Ben-Nissan, "Natural Bioceramics: From Coral to Bone and Beyond,' Curr. Opinion Solid State Mater. Sci., 7 [4-5] 283-8 (2003).

${ }^{44}$ Z. T. Liu, T. X. Fan, W. Zhang, and D. Zhang, "The Synthesis of Hierarchical Porous Iron Oxide with Wood Templates," Microporous Mesoporous Mater., 85 [1-2] 82-8 (2005).

${ }^{45}$ T. Ota, M. Imaeda, H. Takase, M. Kobayashi, N. Kinoshita, T. Hirashita, H. Miyazaki, and Y. Hikichi, "Porous Titania Ceramic Prepared by Mimicking Silicified Wood," J. Am. Ceram. Soc., 83 [6] 1521-3 (2000).

${ }^{46}$ M. Mizutani, H. Takase, N. Adachi, T. Ota, K. Daimon, and Y. Hikichi, "Porous Ceramics Prepared by Mimicking Silicified Wood," Sci. Technol. Adv. Mater., 6 [1] 76-83 (2005)

${ }^{47}$ J. Cao, C. R. Rambo, and H. Sieber, "Manufacturing of Microcellular, Biomorphous Oxide Ceramics from Native Pine Wood," Ceram. Int., 30 [7] 1967-70 (2004).

${ }^{48}$ J. Cao, O. Rusina, and H. Sieber, "Processing of Porous $\mathrm{TiO}_{2}-$ Ceramics from Biological Preforms," Ceram. Int., 30 [7] 1971-4 (2004).

${ }^{49}$ T. Ota, M. Takahashi, T. Hibi, M. Ozawa, S. Suzuki, Y. Hikichi, and H. Suzuki, "Biomimetic Process for Producing SiC "Wood"," J. Am. Ceram. Soc., 78 [12] 3409-11 (1995).

${ }^{50}$ U. Vogt, A. Herzog, T. Graule, R. Klingner, and T. Zimmermann, "Porous Ceramics Derived from Wood"; pp. 1941-4 in Euro Ceramics VII, Part 1-3. Trans Tech Publications Ltd.: Zurich-Uetikon, 2002.

${ }^{51}$ C. R. Rambo, J. Cao, O. Rusina, and H. Sieber, "Manufacturing of Biomorphic (Si, Ti, Zr)-Carbide Ceramics by Sol-Gel Processing," Carbon, 43 [6] 1174-83 (2005).

${ }^{52}$ H. Sieber, C. Hoffmann, A. Kaindl, and P. Greil, "Biomorphic Cellular Ceramics," Adv. Eng. Mater., 2 [3] 105-9 (2000).

${ }^{53}$ J. M. Qian, J. P. Wang, and Z. H. Jin, "Preparation of Biomorphic SiCCeramics by the Reactive Infiltration on of Si into Carbon Template Derived from Basswood," Rare Metal Mater. Eng., 33 [10] 1065-8 (2004).

${ }^{54}$ F. M. Varela-Feria, J. Martinez-Fernandez, A. R. de Arellano-Lopez, and M. Singh, "Low Density Biomorphic Silicon Carbide: Microstructure and Mechanical Properties," J. Eur. Ceram. Soc., 22 [14-15] 2719-25 (2002).

${ }^{55}$ P. Greil, T. Lifka, and A. Kaindl, "Biomorphic Cellular Silicon Carbide Ceramics from Wood: I. Processing and Microstructure," J. Eur. Ceram. Soc., 18 [14] 1961-73 (1998).

A. Zampieri, H. Sieber, T. Selvam, G. T. P. Mabande, W. Schwieger, F. Scheffler, M. Scheffler, and P. Greil, "Biomorphic Cellular SiSiC/Zeolite Ceramic Composites: From Rattan Palm to Bioinspired Structured Monoliths for Catalysis and Sorption," Adv. Mater., 17 [3] 344 (2005).

${ }^{57}$ E. Vogli, H. Sieber, and P. Greil, "Biomorphic SiC-Ceramic Prepared by $\mathrm{Si}-$ Vapor Phase Infiltration of Wood," J. Eur. Ceram. Soc., 22 [14-15] 2663-8 (2002)

${ }^{58}$ C. R. Rambo and H. Sieber, "Novel Synthetic Route to Biomorphic $\mathrm{Al}_{2} \mathrm{O}_{3}$ Ceramics," Adv. Mater., 17 [8] 1088 (2005).

${ }^{59}$ N. Popovska, D. A. Streitwieser, C. Xu, and H. Gerhard, "Paper Derived Biomorphic Porous Titanium Carbide and Titanium Oxide Ceramics Produced by Chemical Vapor Infiltration and Reaction (CVI-R)," J. Eur. Ceram. Soc., 25 [6] 829-36 (2005)

${ }^{60}$ N. Popovska, D. Almeida-Streitwieser, C. Xu, H. Gerhard, and H. Sieber, "Kinetic Analysis of the Processing of Porous Biomorphic Titanium Carbide Ceramics by Chemical Vapor Infiltration," Chem. Vapor Deposition, 11 [3] 153-8 (2005).

${ }^{61}$ D. A. Streitwieser, N. Popovska, H. Gerhard, and G. Emig, "Application of the Chemical Vapor Infiltration and Reaction (M-R) Technique for the Preparation of Highly Porous Biomorphic SiC Ceramics Derived from Paper," J. Eur. Ceram. Soc., 25 [6] 817-28 (2005).

${ }^{62}$ A. Herzog, R. Klingner, U. Vogt, and T. Graule, "Wood-Derived Porous SiC Ceramics by Sol Infiltration and Carbothermal Reduction," J. Am. Ceram. Soc., 87 [5] 784-93 (2004).

${ }^{63}$ C. Zollfrank, R. Kladny, H. Sieber, and P. Greil, "Biomorphous SiOC/CCeramic Composites from Chemically Modified Wood Templates," J. Eur. Ceram. Soc., 24 [2] 479-87 (2004).

${ }^{64}$ A. G. Dong, Y. J. Wang, Y. Tang, N. Ren, Y. H. Zhang, J. H. Yue, and Z. Gao, "Zeolitic Tissue Through Wood Cell Templating," Adv. Mater., 14 [12] 9269 (2002)

${ }^{65}$ L. M. Rodriguez-Lorenzo and K. A. Gross, "Calcium Phosphate Porous Scaffolds from Natural Materials"; pp. 957-60 in Bioceramics, Vol. 16, Key Engineering Materials. Edited by M. A. Barbosa, R. Correia, and B. Leon. Transtech Publications Ltd.: Zurich-Uetikon, 2004.

${ }^{66}$ M. D. M. Innocentini, P. Sepulveda, V. R. Salvini, V. C. Pandolfelli, and J. R. Coury, "Permeability and Structure of Cellular Ceramics: A Comparison Between Two Preparation Techniques," J. Am. Ceram. Soc., 81 [12] 3349-52 (1998).

${ }^{67} \mathrm{P}$. Colombo and J. R. Hellmann, "Ceramic Foams from Preceramic Polymers," Mater. Res. Innovations, 6 [5-6] 260-72 (2002).

${ }^{68}$ P. Sepulveda, "Gelcasting Foams for Porous Ceramics," Am. Ceram. Soc. Bull., 76 [10] 61-5 (1997).

${ }^{69}$ I. Fukuura and T. Asano, "Fabrication and Properties of Some Oxide Ceramics: Alumina, Mullite and Zirconia”; pp. 165-74 in Fine Ceramics, Edited by S. Saito. Elsevier, New York, 1985.
${ }^{70}$ Y. W. Kim, M. Mitomo, H. Emoto, and J. G. Lee, "Effect of Initial AlphaPhase Content on Microstructure and Mechanical Properties of Sintered Silicon Carbide," J. Am. Ceram. Soc., 81 [12] 3136-40 (1998).

${ }^{71}$ P. Greil, “Active-Filler-Controlled Pyrolysis of Preceramic Polymers," J. Am. Ceram. Soc., 78 [4] 835-48 (1995).

${ }^{72}$ J. Li, S. Forberg, and L. Hermansson, "Evaluation of the MechanicalProperties of Hot Isostatically Pressed Titania and Titania Calcium-Phosphate Composites," Biomaterials, 12 [4] 438-40 (1991).

${ }^{73}$ M. Akao, H. Aoki, and K. Kato, "Mechanical-Properties of Sintered Hydroxyapatite for Prosthetic Applications," J. Mater. Sci., 16 [3] 809-12 (1981).

${ }^{74}$ M. Mizuno, "Microstructure, Microchemistry, and Flexural Strength of Mullite Ceramics," J. Am. Ceram. Soc., 74 [12] 3017-22 (1991).

${ }^{75}$ S. Kanzaki, H. Tabata, T. Kumazawa, and S. Ohta, "Sintering and Mechanical-Properties of Stoichiometric Mullite," J. Am. Ceram. Soc., 68 [1] C6-7 (1985).

${ }^{76}$ L. J. Gibson and M. F. Ashby, Cellular Solids: Structure and Properties, p. 510. 2nd edition, Cambridge University Press, Cambridge, 1997.

${ }^{77}$ M. X. Wu and G. L. Messing, "Sic-Whisker-Reinforced Cellular $\mathrm{Sio}_{2}$ Composites," J. Am. Ceram. Soc., 73 [11] 3497-9 (1990).

${ }^{78}$ R. E. Newnham and G. R. Ruschau, "Smart Electroceramics," J. Am. Ceram. Soc., 74 [3] 463-80 (1991).

${ }^{79}$ P. Greil, "Biomorphous Ceramics from Lignocellulosics," J. Eur. Ceram. Soc., 21 [2] 105-18 (2001).

${ }^{80}$ C. Zollfrank, N. Travitzky, H. Sieber, T. Selchert, and P. Greil, "Biomorphous $\mathrm{SiSiC} / \mathrm{Al}-\mathrm{Si}$ Ceramic Composites Manufactured by Squeeze Casting: Microstructure and Mechanical Properties," Adv. Eng. Mater., 7 [8] 743-6 (2005).

${ }^{81}$ F. Caruso, "Hollow Capsule Processing Through Colloidal Templating and Self-Assembly," Chemistry-A Eur. J., 6 [3] 413-9 (2000).

${ }^{82}$ V. Valtchev, M. Smaihi, A. C. Faust, and L. Vidal, "Dual Templating Function of Equisetum Arvense in the Preparation of Zeolite Macrostructures", pp. 588-92 in Recent Advances in the Science and Technology of Zeolites and Related Materials, Parts A-C, Studies in Surface Science and Catalysis. Edited by E. VanSteen and L. H. Callanan. Elsevier: Amsterdam, 2004.

${ }^{83}$ V. P. Valtchev, M. Smaihi, A. C. Faust, and L. Vidal, "Equisetum Arvense Templating of Zeolite Beta Macrostructures with Hierarchical Porosity," Chem. Mater., 16 [7] 1350-5 (2004).

${ }^{84}$ D. Yang, L. M. Qi, and J. M. Ma, "Hierarchically Ordered Networks Comprising Crystalline $\mathrm{ZrO}_{2}$ Tubes Through Sol-Gel Mineralization of Eggshell Membranes," J. Mater. Chem., 13 [5] 1119-23 (2003).

${ }^{85}$ D. Yang, L. M. Qi, and J. M. Ma, "Eggshell Membrane Templating of Hierarchically Ordered Macroporous Networks Composed of $\mathrm{TiO}_{2}$ Tubes," Adv. Mater., 14 [21] 1543 (2002).

${ }^{86}$ K. H. Sandhage, M. B. Dickerson, P. M. Huseman, M. A. Caranna, J. D Clifton, T. A. Bull, T. J. Heibel, W. R. Overton, and M. E. A. Schoenwaelder, "Novel, Bioclastic Route to Self-Assembled, 3D, Chemically Tailored Meso/ Nanostructures: Shape-Preserving Reactive Conversion of Biosilica (Diatom) Microshells," Adv. Mater., 14 [6] 429 (2002).

${ }^{87}$ P. Colombo, E. Bernardo, and L. Biasetto, "Novel Microcellular Ceramics from a Silicone Resin," J. Am. Ceram. Soc., 87 [1] 152-4 (2004).

${ }^{88}$ O. Lyckfeldt and J. M. F. Ferreira, "Processing of Porous Ceramics by Starch Consolidation," J. Eur. Ceram. Soc., 18 [2] 131-40 (1998).

${ }^{89}$ T. J. Fitzgerald, V. J. Michaud, and A. Mortensen, "Processing of Microcellular Sic Foams. 2. Ceramic Foam Production," J. Mater. Sci., 30 [4] 1037-45 (1995).

${ }^{90}$ R. A. Lopes and A. M. Segadaes, "Microstructure, Permeability and Mechanical Behaviour of Ceramic Foams," Mater. Sci. Eng. A-Struct. Mater. Prop. Microstruct. Process., 209 [1-2] 149-55 (1996).

${ }^{91}$ B. P. Kumar, H. H. Kumar, and D. K. Kharat, "Study on Pore-Forming Agents in Processing of Porous Piezoceramics," J. Mater. Sci--Mater. Electronics, 16 [10] 681-6 (2005).

${ }^{92}$ Y. Hotta, P. C. A. Alberius, and L. Bergstrom, "Coated Polystyrene Particles as Templates for Ordered Macroporous Silica Structures with Controlled Wall Thickness," J. Mater. Chem., 13 [3] 496-501 (2003).

${ }^{93}$ Y. Hotta, "Silica Honeycomb-Crystal Structure Prepared by Fabrication of Silica-Coated Particles"; pp. 186-91 in Eco-Materials Processing \& Design, Materials Science Forum. Edited by H. S. Kim and S. W. Lee. Trans Tech Publications Ltd.: Zurich-Uetikon, 2003.

${ }^{94}$ D. Y. Wang, R. A. Caruso, and F. Caruso, "Synthesis of Macroporous Titania and Inorganic Composite Materials from Coated Colloidal Spheres - A Novel Route to Tune Pore Morphology," Chem. Mater., 13 [2] 364-71 (2001).

${ }^{95}$ D. B. Kuang, A. W. Xu, J. Y. Zhu, H. Q. Liu, and B. S. Kang, "Fabrication of Ordered Macroporous Rutile Titania at Low Temperature," N. J. Chem., 26 [7] 819-21 (2002).

${ }^{96}$ P. G. Ni, B. Y. Cheng, P. Dong, and D. Z. Zhang, "A Novel Titania Membrane with Uniform Macropores," Chinese Phys. Lett., 18 [12] 1610-2 (2001)

${ }^{97}$ S. A. Davis, M. Breulmann, K. H. Rhodes, B. Zhang, and S. Mann, "Template-Directed Assembly Using Nanoparticle Building Blocks: A Nanotectonic Approach to Organized Materials," Chem. Mater., 13 [10] 3218-26 (2001).

${ }^{98}$ I. Thijs, J. Luyten, and S. Mullens, "Producing Ceramic Foams with Hollow Spheres," J. Am. Ceram. Soc., 87 [1] 170-2 (2004).

${ }^{99}$ D. M. Liu, "Influence of Porosity and Pore Size on the Compressive Strength of Porous Hydroxyapatite Ceramic," Ceram. Int., 23 [2] 135-9 (1997).

${ }^{100}$ P. Colombo and E. Bernardo, "Macro- and Micro-Cellular Porous Ceramics from Preceramic Polymers," Composites Sci. Technol., 63 [16] 2353-9 (2003).

${ }^{101}$ Y. W. Kim, S. H. Kim, and C. B. Park, "Processing of Closed-Cell Silicon Oxycarbide Foams from a Preceramic Polymer," J. Mater. Sci., 39 [18] 5647-52 (2004). 
${ }^{102}$ Y. W. Kim, Y. J. Jin, Y. S. Chun, I. H. Song, and H. D. Kim, "A Simple Pressing Route to Closed-Cell Microcellular Ceramics," Scripta Mater., 53 [8] 921-5 (2005)

${ }^{103}$ S. H. Li, J. R. de Wijn, P. Layrolle, and K.de Groot, "Novel Method to Manufacture Porous Hydroxyapatite by Dual-Phase Mixing," J. Am. Ceram. Soc., 86 [1] 65-72 (2003).

${ }^{104}$ S. H. Li, J. R. De Wijn, P. Layrolle, and K.de Groot, "Synthesis of Macroporous Hydroxyapatite Scaffolds for Bone Tissue Engineering," J. Biomedical Mater. Res., 61 [1] 109-20 (2002).

${ }^{105}$ N. Koc, M. Timucin, and F. Korkusuz, "Fabrication and Characterization of Porous Tricalcium Phosphate Ceramics," Ceram. Int., 30 [2] 205-11 (2004).

${ }^{106}$ Y. W. Kim, S. H. Kim, I. H. Song, H. D. Kim, and C. B. Park, "Fabrication of Open-Cell, Microcellular Silicon Carbide Ceramics by Carbothermal Reduction," J. Am. Ceram. Soc., 88 [10] 2949-51 (2005).

${ }^{107}$ H. F. Yang, G. J. Zhang, N. Kondo, T. Ohji, and S. Kanzaki, "Synthesis of Porous $\mathrm{Si}_{3} \mathrm{~N}_{4}$ Ceramics with Rod-Shaped Pore Structure," J. Am. Ceram. Soc., 88 [4] 1030-2 (2005).

${ }^{108}$ H. Wang, I. Y. Sung, X. D. Li, and D. Kim, "Fabrication of Porous SiC Ceramics with Special Morphologies by Sacrificing Template Method,' J. Porous Mater., 11 [4] 265-71 (2004).

${ }^{109}$ N. W. Androff, L. F. Francis, and B. V. Velamakanni, "Macroporous Ceramics from Ceramic-Polymer Dispersion Methods," A.I.Ch.E. J., 43 [1] 2878-88 (1997).

${ }^{110}$ J. M. Bouler, M. Trecant, J. Delecrin, J. Royer, N. Passuti, and G. Daculsi, "Macroporous Biphasic Calcium Phosphate Ceramics: Influence of Five Synthesis Parameters on Compressive Strength," J. Biomed. Mater. Res., 32 [4] 603-9 (1996).

${ }^{111}$ G. J. Zhang, J. F. Yang, and T. Ohji, "Fabrication of Porous Ceramics with Unidirectionally Aligned Continuous Pores," J. Am. Ceram. Soc., 84 [6] 1395-7 (2001).

${ }^{112}$ S. M. Naga, A. A. El-Maghraby, A. M. El-Rafei, P. Greil, T. Khalifa, and N. A. Ibrahim, "Porous Fibrous Mullite Bodies," Am. Ceram. Soc. Bull., 85 [2] 21-4 (2006).

${ }^{113}$ C. Wang, T. Kasuga, and M. Nogami, "Macroporous Calcium Phosphate Glass-Ceramic Prepared by Two-Step Pressing Technique and Using Sucrose as a Pore Former," J. Mater. Sci.-Mater. Med., 16 [8] 739-44 (2005).

${ }^{114}$ Y. Sun, S. H. Tan, and D. L. Jiang, "Synthesis of Porous Silicon Carbide and its Catalysis," J. Inorganic Mater., 18 [4] 830-6 (2003).

${ }^{115}$ M. H. P. da Silva, A. F. Lemos, I. R. Gibson, J. M. F. Ferreira, and J. D. Santos, "Porous Glass Reinforced Hydroxyapatite Materials Produced with Different Organic Additives," J. Non-Cryst. Solids, 304 [1-3] 286-92 (2002).

${ }^{116}$ H. Katsuki, A. Kawahara, and H. Ichinose, "Preparation and Some Properties of Porous Alumina Ceramics Obtained by the Gelatination of Ammonium Alginate," J. Mater. Sci., 27 [22] 6067-70 (1992).

${ }^{117}$ M. E. Bowden and M. S. Rippey, "Porous Ceramics Formed Using Starch Consolidation"; pp. 1957-60 in Euro Ceramics VII, Part 1-3, Key Engineering Materials. Trans Tech Publications Ltd.: Zurich-Uetikon, 2002.

${ }^{118}$ J. Luyten, J. Cooymans, A. De Wilde, and I. Thijs, "Porous Materials, Synthesis and Characterization"; pp. 1937-40 in Euro Ceramics VII, Part 1-3, Key Engineering Materials. Trans Tech Publications Ltd.: Zurich-Uetikon, 2002.

${ }^{119}$ C. Galassi, C. Capiani, F. Craciun, and E. Roncari, "Water-Based Technique to Produce Porous PZT Materials," J.Phys. IV, 128, 27-31 (2005).

${ }^{120}$ L. M. Rodriguez-Lorenzo, M. Vallet-Regi, and J. M. F. Ferreira, "Fabrication of Porous Hydroxyapatite Bodies by a New Direct Consolidation Method: Starch Consolidation," J. Biomed. Mater. Res., 60 [2] 232-40 (2002).

${ }^{121}$ L. Yang, X. S. Ning, K. X. Chen, Q. F. Xiao, and H. P. Zhou, "Preparation of Porous Hydroxyapatite Ceramics with Starch Additives," Trans. Nonferrous Metals Soc. China, 15 [2] 257-60 (2005).

${ }^{122}$ R. Barea, M. I. Osendi, P. Miranzo, and J. M. F. Ferreira, "Fabrication of Highly Porous Mullite Materials," J. Am. Ceram. Soc., 88 [3] 777-9 (2005).

${ }^{123}$ A. Diaz and S. Hampshire, "Characterisation of Porous Silicon Nitride Materials Produced with Starch,” J. Eur. Ceram. Soc., 24 [2] 413-9 (2004).

${ }^{124}$ A. F. Lemos and J. M. F. Ferreira, "Porous Bioactive Calcium Carbonate Implants Processed by Starch Consolidation," Mater. Sci. Eng. C-Biomimetic Supramolecular Systems, 11 [1] 35-40 (2000).

${ }^{125}$ P. V. Vasconcelos, J. A. Labrincha, and J. M. F. Ferreira, "Permeability of Diatomite Layers Processed by Different Colloidal Techniques," J. Eur. Ceram. Soc., 20 [2] 201-7 (2000).

${ }^{126}$ H. M. Alves, G. Tari, A. T. Fonseca, and J. M. F. Ferreira, "Processing of Porous Cordierite Bodies by Starch Consolidation," Mater. Res. Bull., 33 [10] 1439-48 (1998).

${ }^{127}$ O. Lyckfeldt, E. Liden, and R. Vcarlsson, "Processing of Thermal Insulation Materials With Controlled Porosity"; pp. 217-28 in Ceramic Transactions, LowExpansion Materials, Edited by D. P. Stinton, and S. Y. Limaye. The American Ceramic Society, Westerville, 1995.

${ }^{128} \mathrm{~K}$. Araki and J. W. Halloran, "Porous Ceramic Bodies with Interconnected Pore Channels by a Novel Freeze Casting Technique," J. Am. Ceram. Soc., 88 [5] 1108-14 (2005)

${ }^{129}$ T. Fukasawa, M. Ando, T. Ohji, and S. Kanzaki, "Synthesis of Porous Ceramics with Complex Pore Structure by Freeze-Dry Processing," J. Am. Ceram. Soc., 84 [1] 230-2 (2001).

${ }^{130}$ T. Fukasawa, Z. Y. Deng, M. Ando, T. Ohji, and Y. Goto, "Pore Structure of Porous Ceramics Synthesized from Water-Based Slurry by Freeze-Dry Process," J. Mater. Sci., 36 [10] 2523-7 (2001).

${ }^{131}$ S. R. Mukai, H. Nishihara, and H. Tamon, "Formation of Monolithic Silica Gel Microhoneycombs (SMHs) Using Pseudosteady State Growth of Microstructural Ice Crystals," Chem. Commun., [7] 874-5 (2004).
${ }^{132}$ T. Fukasawa, Z. Y. Deng, M. Ando, T. Ohji, and S. Kanzaki, "Synthesis of Porous Silicon Nitride with Unidirectionally Aligned Channels Using FreezeDrying Process," J. Am. Ceram. Soc., 85 [9] 2151-5 (2002).

${ }^{133}$ D. Koch, L. Andresen, T. Schmedders, and G. Grathwohl, "Evolution of Porosity by Freeze Casting and Sintering of Sol-Gel Derived Ceramics," J. Sol Gel Sci. Technol., 26 [1-3] 149-52 (2003).

${ }^{134} \mathrm{~A}$. Imhof and D. J. Pine, "Ordered Macroporous Materials by Emulsion Templating," Nature, 389 [6654] 948-51 (1997).

${ }^{135}$ A. Imhof and D. J. Pine, "Preparation of Titania Foams," Adv. Mater., 11 [4] 311-4 (1999)

${ }^{136}$ I. Akartuna, A. R. Studart, U. T. Gonzenbach, E. Tervoort, and L. J. Gauckler, "Porous Ceramics from Particle-Stabilized Emulsions," Adv. Mater., (2006), in Preparation.

${ }^{137}$ C. Ritzoulis, N. Scoutaris, K. Papademetriou, S. Stavroulias, and C. Panayiotou, "Milk Protein-Based Emulsion Gels for Bone Tissue Engineering," Food Hydrocolloids, 19 [3] 575-81 (2005).

${ }^{138}$ B. P. Binks, "Macroporous Silica from Solid-Stabilized Emulsion Templates," Adv. Mater., 14 [24] 1824-7 (2002).

${ }^{139}$ D. Walsh and S. Mann, "Synthesis of Cellular Inorganic Films from SelfOrganized Media," Adv. Mater., 9 [8] 658-62 (1997).

${ }^{140}$ Y. Beppu, M. Ando, and T. Ohji, "Control of Porosity and Pore Size for Porous Alumina Prepared from Alpha-Alumina, $\mathrm{BaSO}_{4}$ and $/$ or $\mathrm{SrSO}_{4}$, , Int. J. Mater. Product Technol., 209-14 (2001).

${ }^{141}$ E. S. Toberer, J. C. Weaver, K. Ramesha, and R. Seshadri, "Macroporous Monoliths of Functional Perovskite Materials Through Assisted Metathesis," Chem. Mater., 16 [11] 2194-200 (2004).

${ }^{142}$ H. Kim, C. da Rosa, M. Boaro, J. M. Vohs, and R. J. Gorte, "Fabrication of Highly Porous Yttria-Stabilized Zirconia by Acid Leaching nickel from a Nickel-Yttria-Stabilized Zirconia Cermet," J. Am. Ceram. Soc., 85 [6] 1473-6 (2002).

${ }^{143}$ N. Miyagawa and N. Shinohara, "Fabrication of Porous Alumina Ceramics with Uni-Directionally-Arranged Continuous Pores Using a Magnetic Field," $J$ Ceram. Soc. Jpn., 107 [7] 673-7 (1999).

${ }^{144}$ J. H. She, J. F. Yang, and T. Ohji, "Reaction Bonding of Porous Mullite Ceramics"; pp. 223-6 in Advanced Ceramics and Composites, Key Engineering Materials. Trans Tech Publications Ltd., Zurich-Uetikon, 2003.

${ }^{145}$ M. Rajamathi, S. Thimmaiah, P. E. D. Morgan, and R. Seshadri, "Macroporous Materials from Crystalline Single-Source Precursors Through Decomposition Followed by Selective Leaching," J. Mater. Chem., 11 [10] 2489-92 (2001).

${ }^{146}$ K. M. Lindquist and E. Carlstrom, "Indirect Solid freeform Fabrication by Binder Assisted Slip Casting," J. Eur. Ceram. Soc., 25 [16] 3539-45 (2005).

${ }^{147}$ T. J. Fitzgerald and A. Mortensen, "Processing of Microcellular SiC Foams 1. Curing Kinetics of Polycarbosilane in Air," J. Mater. Sci., 30 [4] 1025-32 (1995).

${ }^{148}$ P. C. Hiemenz and R. Rayagopalan, Principles of Colloid and Surface Chemistry, p. 650. 3rd edition, Marcel Dekker Inc, New York, 1997.

${ }^{149}$ R. J. Pugh, "Foams and Foaming"; pp. 23-43 in Handbook of Applied Surface and Colloid Chemistry, Vol. 2. Edited by K. Holmberg. John Wiley \& Sons Ltd, West Sussex, 2001.

${ }^{150}$ Z. P. Du, M. P. Bilbao-Montoya, B. P. Binks, E. Dickinson, R. Ettelaie, and B. S. Murray, "Outstanding Stability of Particle-Stabilized Bubbles," Langmuir, 19 [8] 3106-8 (2003)

E. Dickinson, R. Ettelaie, T. Kostakis, and B. S. Murray, "Factors Controlling the Formation and Stability of Air Bubbles Stabilized by Partially Hydrophobic Silica Nanoparticles," Langmuir, 20 [20] 8517-25 (2004).

${ }^{152}$ B. P. Binks and T. S. Horozov, "Aqueous Foams Stabilized Solely by Silica Nanoparticles," Angewandte Chemie-Int. Ed., 44 [24] 3722-5 (2005).

${ }^{153}$ U. T. Gonzenbach, A. R. Studart, E. Tervoort, and L. J. Gauckler, "Ultrastable particle-stabilized foams," Angewandte Chemie - Int. Ed., (2006), in press.

${ }^{154}$ S. U. Pickering, "Emulsions," J. Chem. Soc., 91, 2001-21 (1907).

${ }^{155}$ B. M. Moudgil, P. K. Singh, and J. J. Adler, "Surface Chemistry in Dispersion, Flocculation and Flotation"; pp. 219-49 in Handbook of Applied Surface and Colloid Chemistry, Vol. 1. Edited by K. Holmberg. John Wiley \& Sons Ltd, West Sussex, 2002

${ }^{156}$ B. P. Binks, "Particles as Surfactants - Similarities and Differences," Curr. Opin. Colloid Interf. Sci., 7 [1-2] 21-41 (2002).

${ }^{157}$ L. A. Pugnaloni, E. Dickinson, R. Ettelaie, A. R. Mackie, and P. J. Wilde, "Competitive Adsorption of Proteins and Low-Molecular-Weight Surfactants: Computer Simulation and Microscopic Imaging," Adv. Colloid Interf. Sci., 107 [1] 27-49 (2004).

${ }^{158}$ P. Sepulveda and J. G. P. Binner, "Processing of Cellular Ceramics by Foaming and In Situ Polymerisation of Organic Monomers," J. Eur. Ceram. Soc., 19 [12] 2059-66 (1999).

${ }^{159}$ E. P. Santos, C. V. Santilli, and S. H. Pulcinelli, "Formation of Zirconia Foams Using the Thermostimulated Sol-Gel Transition," J. Non-Crystalline Solids, 304 [1-3] 143-50 (2002).

${ }^{160}$ F. S. Ortega, P. Sepulveda, M. D. M. Innocentini, and V. C. Pandolfelli, "Surfactants: A Necessity for Producing Porous Ceramics," Am. Ceram. Soc. Bull., 80 [4] 37-42 (2001).

${ }^{161}$ P. Colombo and M. Modesti, "Silicon Oxycarbide Ceramic Foams from a Preceramic Polymer," J. Am. Ceram. Soc., 82 [3] 573-8 (1999).

${ }^{162}$ T. Fujiu, G. L. Messing, and W. Huebner, "Processing and Properties of Cellular Silica Synthesized by Foaming Sol Gels," J. Am. Ceram. Soc., 73 [1] 85-90 (1990)

${ }^{163}$ T. Tomita, S. Kawasaki, and K. Okada, "A Novel Preparation Method for Foamed Silica Ceramics by Sol-Gel Reaction and Mechanical Foaming," $J$. Porous Mater., 11 [2] 107-15 (2004).

${ }^{164}$ S. Dhara and P. Bhargava, "A Simple Direct Casting Route to Ceramic Foams," J. Am. Ceram. Soc., 86 [10] 1645-50 (2003). 
${ }^{165}$ J. A. Delgado, I. Harr, A. Almirall, S. del Valle, J. A. Planell, and M. P. Ginebra, "Injectability of a Macroporous Calcium Phosphate Cement"; pp. 15760 in Bioceramics, Vol. 17, Key Engineering Materials. Edited by P. Li and C. W. Colwell. Trans Tech Publications Ltd., Zurich-Uetikon, 2005.

${ }^{166}$ T. Takahashi, H. Munstedt, P. Colombo, and M. Modesti, "Thermal Evolution of a Silicone Resin/Polyurethane Blend from Preceramic to Ceramic Foam," J. Mater. Sci., 36 [7] 1627-39 (2001).

${ }^{167}$ X. Bao, M. R. Nangrejo, and M. J. Edirisinghe, "Synthesis of Silicon Carbide Foams from Polymeric Precursors and their Blends," J. Mater. Sci., 34 [11] 2495 505 (1999).

${ }^{168}$ W. P. Minnear, "Processing of Foam Ceramics"; pp. 146-56 in Forming Science and Technology for Ceramics, Edited by M. J. Cima. American Ceramic Society, Westerville, 1992.

${ }^{169}$ H. X. Peng, Z. Fan, J. R. G. Evans, and J. J. C. Busfield, "Microstructure of Ceramic Foams," J. Eur. Ceram. Soc., 20 [7] 807-13 (2000).

${ }^{170}$ H. X. Peng, Z. Fan, and J. R. G. Evans, "Cellular Arrays of Alumina Fibres," J. Mater. Sci., 36 [4] 1007-13 (2001).

${ }^{171}$ H. X. Peng, Z. Fan, and J. R. G. Evans, "Factors Affecting the Microstructure of a Fine Ceramic Foam," Ceram. Int., 26 [8] 887-95 (2000).

${ }^{172}$ S. J. Powell and J. R. G. Evans, "The Structure of Ceramic Foams Prepared from Polyurethane-Ceramic Suspensions," Mater. Manufacturing Processes, 10 [4] 757-71 (1995).

${ }^{173}$ E. Ebaretonbofa and J. R. G. Evans, "High Porosity Hydroxyapatite Foam Scaffolds for Bone Substitute," J. Porous Mater., 9 [4] 257-63 (2002).

${ }^{174}$ L. L. Wood, P. Messina, and K. Frisch. "Method of Preparing Porous Ceramic Structures by Firing a Polyurethane Foam that is Impregnated with Organic Materia." U.S. Patent, 1974.

${ }^{75}$ E. Williams and J. R. G. Evans, "Expanded Ceramic Foam," J. Mater. Sci., 31 [3] 559-63 (1996).

${ }^{176}$ Y. W. Kim, S. H. Kim, X. Xu, C. H. Choi, C. B. Park, and H. D. Kim "Fabrication of Porous Preceramic Polymers Using Carbon Dioxide," J. Mater. Sci. Lett., 21 [21] 1667-9 (2002).

${ }^{177}$ Y. W. Kim and C. B. Park, "Processing of Microcellular Preceramics Using Carbon Dioxide," Composites Sci. Technol., 63 [16] 2371-7 (2003).

${ }^{178}$ J. Zeschky, T. Hofner, C. Arnold, R. Weissmann, D. Bahloul-Hourlier, M. Scheffler, and P. Greil, "Polysilsesquioxane Derived Ceramic Foams with Gradient Porosity," Acta Mater., 53 [4] 927-37 (2005).

${ }^{179}$ J. Zeschky, F. Goetz-Neunhoeffer, J. Neubauer, S. H. J. Lo, B. Kummer, M. Scheffler, and P. Greil, "Preceramic Polymer Derived Cellular Ceramics," Composites Sci. Technol., 63 [16] 2361-70 (2003).

${ }^{180}$ T. Takahashi and P. Colombo, "SiOC Ceramic Foams Through Melt Foaming of a Methylsilicone Preceramic Polymer," J. Porous Mater., 10 [2] 113-21 (2003).

${ }^{181}$ Y. W. Kim, K. H. Lee, S. H. Lee, and C. B. Park, "Fabrication of Porous Silicon Oxycarbide Ceramics by Foaming Polymer Liquid and Compression Molding," J. Ceram. Soc. Jpn., 111 [11] 863-4 (2003).

${ }^{182}$ P. Sepulveda, J. R. Jones, and L. L. Hench, "Bioactive Sol-Gel Foams for Tissue Repair," J. Biomedical Mater. Res., 59 [2] 340-8 (2002).

${ }^{183}$ P. Sepulveda and L. L. Hench, Production of Foamed Bioactive Sol-Gel Involves Hydrolyzing Reaction Mixture Comprising Metal Alkoxides with Acidic Catalyst, Foaming by Vigorous Agitation with Surfactants, Aging, Drying and Thermally Stabilizing the Sol-Gel. 2004, United States, US patent Application No. 2004/0241238 A1, Imperial College Innovations Ltd (IMCO-Non-standard).

${ }^{184}$ G. T. Chandrappa, N. Steunou, and J. Livage, "Materials ChemistryMacroporous Crystalline Vanadium Oxide Foam," Nature, 416 [6882] 702 (2002)

${ }^{185}$ E. P. Santos, C. V. Santilli, and S. H. Pulcinelli, "Effect of Aging on the Stability of Ceramic Foams Prepared by Thermostimulated Sol-Gel Process," $J$. Sol-Gel Sci. Technol., 26 [1-3] 165-9 (2003).

${ }^{186}$ G. S. Grader, G. E. Shter, and Y. de Hazan, "Novel Ceramic Foams from Crystals of $\mathrm{AlCl}_{3}\left(\left(\mathrm{Pr}_{2} \mathrm{O}\right)-\mathrm{O}-\mathrm{i}\right)$ Complex," J. Mater. Res., 14 [4] 1485-94 (1999).

${ }^{187}$ J. G. P. Binner, "Production and Properties of Low Density Engineering Ceramic Foams," Br. Ceram. Trans., 96 [6] 247-9 (1997).

${ }^{188}$ F. S. Ortega, P. Sepulveda, and V. C. Pandolfelli, "Monomer Systems for the Gelcasting of Foams," J. Eur. Ceram. Soc., 22 [9-10] 1395-401 (2002)

${ }^{189}$ P. Sepulveda, J. G. P. Binner, S. O. Rogero, O. Z. Higa, and J. C. Bressiani, "Production of Porous Hydroxyapatite by the Gel-Casting of Foams and Cytotoxic Evaluation," J. Biomedical Mater. Res., 50 [1] 27-34 (2000).

${ }^{190}$ J. G. P. Binner and J. Reichert, "Processing of Hydroxyapatite Ceramic Foams," J. Mater. Sci., 31 [21] 5717-23 (1996).

${ }^{191}$ F. S. Ortega, J. A. Rodrigues, and V. C. Pandolfelli, "Strength of Gelcast Ceramic Foams," Am. Ceram. Soc. Bull., 83 [3] 9501-6 (2004).

${ }^{192}$ I. Garrn, C. Reetz, N. Brandes, L. W. Kroh, and H. Schubert, "ClotForming: The Use of Proteins as Binders for Producing Ceramic Foams," $J$. Eur. Ceram. Soc., 24 [3] 579-87 (2004).

${ }^{193}$ K. Prabhakaran, N. M. Gokhale, S. C. Sharma, and R. Lal, "A Novel Process for Low-Density Alumina Foams," J. Am. Ceram. Soc., 88 [9] 2600-3 (2005)

${ }^{194}$ F. S. Ortega, F. A. O. Valenzuela, C. H. Scuracchio, and V. C. Pandolfelli, "Alternative Gelling Agents for the Gelcasting of Ceramic Foams," J. Eur. Ceram. Soc., 23 [1] 75-80 (2003).

${ }^{195}$ C. Tuck and J. R. G. Evans, "Porous Ceramics Prepared from Aqueous Foams," J. Mater. Sci. Lett., 18 [13] 1003-5 (1999).

${ }^{196}$ S. Dhara, M. Pradhan, D. Ghosh, and P. Bhargava, "Nature Inspired Novel Processing Routes for Ceramic Foams," Adv. Appl. Ceram., 104 [1] 9-21 (2005).

${ }^{7}$ V. R. Salvini, J. R. Garcia, I. R. de Oliveira, and V. C. Pandolfelli, "Foaming Agent and the Effects on the Physical Properties of Porous Alumina (in Portuguese)," Cerâmica, (2006), in press.
${ }^{198}$ F. S. Ortega, J. A. Rodrigues, and V. C. Pandolfelli, "Elastic Modulus of Gelcast Cellular Ceramics at High Temperatures," Am. Ceram. Soc. Bull., 85 [2] 9101-6 (2006).

${ }^{199}$ R. Mouazer, I. Thijs, S. Mullens, and J. Luyten, "SiC Foams Produced by Gel Casting: Synthesis and Characterization," Adv. Eng. Mater., 6 [5] 340-3 (2004)

${ }^{200}$ J. K. Park, J. S. Lee, and S. I. Lee, "Preparation of Porous Cordierite Using Gelcasting Method and its Feasibility as a Filter," J. Porous Mater., 9 [3] 203-10 (2002).

${ }^{201}$ U. T. Gonzenbach, A. R. Studart, E. Tervoort, and L. J. Gauckler, "Macroporous Ceramics from Particle. Stabilized Wet Foams," J. Am. Ceram. Soc. (2006), Submitted.

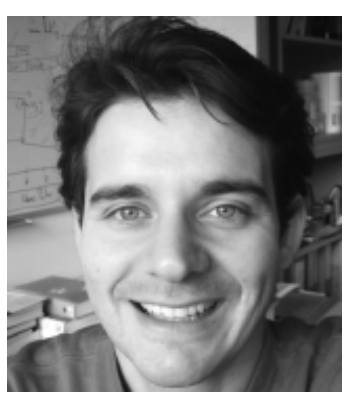

André Studart received his Bachelor degree in Materials Science and Engineering from the Federal University of São Carlos, Brazil. He carried out his Ph.D. with Prof. Pandolfelli in the same university, investigating novel methods for processing refractory castables and near-net-shape advanced ceramics. In 2002 he joined Prof. Gauckler's group at ETH to study the mechanical properties of ceramic materials used in prosthetic dentistry. Currently he is lecturer and research associate at ETH Zurich, and leads the colloid chemistry group at the Inorganic Non-metallic Materials Chair. He was awarded by Alcoa Co., Thermo Haake Co., and Brookfield Co., among others, for his contributions on the processing of refractory and advanced ceramics. He is coauthor of an undergraduate textbook on ceramic processing, holds three patents and has published more than 40 scientific papers in peer-reviewed journals. His main research interests are on colloid chemistry and physics applied to materials science, with emphasis on materials for structural, energy, and biomedical applications.

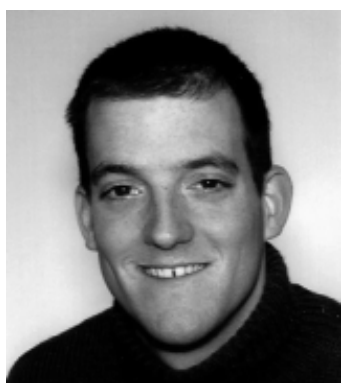

Urs T. Gonzenbach studied materials science at the Swiss Federal Institute of Technology (ETH) in Zurich, Switzerland. Already during his undergraduate studies, he joined Prof. Ludwig Gauckler's group in the Department of Materials at ETH where he started to work on ceramic processing and colloid chemistry. His Ph.D. thesis is focused on using a variety of colloidal particles to stabilize airwater interfaces, allowing for the fabrication of stable wet foams and porous materials with enhanced properties.

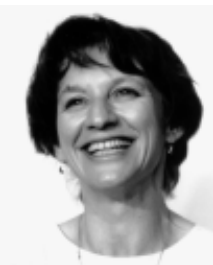

Elena V. Tervoort received her academic degrees in the Moscow Institute of Chemical Technology and in the Institute of Chemical Physics, Russian Academy of Science in Moscow, Russia, where she worked as a research associate from 1985 until 1992. Her Ph.D. thesis was concerned with the modification of polyolefins with siloxane additives and anorganic fillers. After a combined post-doctoral stay at DSMresearch in Geleen, and the Polymer Technology group of the Eindhoven University of Technology, both in the Netherlands, she accepted a position as Assistant Professor in the Nonmetallic Inorganic Materials group of Prof. Gauckler at the Department of Material Science at the ETH Zurich in Switzerland. Her research interests are colloidal aspects of ceramic processing and ceramic foams. 


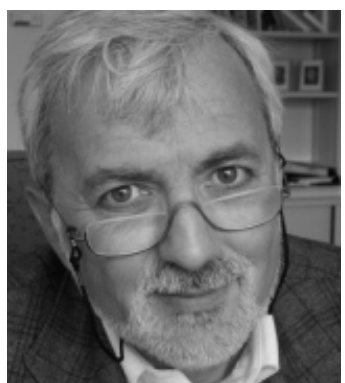

Ludwig J. Gauckler received his degree in physics at the University of Stuttgart and his Ph.D. in materials science in 1977 with a thesis about $\mathrm{SiAlON}$ he performed at the Max Planck Institute for Metals and Materials Research in Stuttgart with Prof. G. Petzow. He then carried out research in the area of high-performance structural and functional ceramics as research associate at the University of Michigan, Ann Arbor in 1977 with Prof. T. Y. Tien. From 1979 to 1988 he was responsible for the inorganic non-metallic materials development in the central laboratories of AlusuisseLonza AG. Since 1988 he is Professor for "Nonmetallic Inorganic Materials" in the Department of Material Science at the ETH Zurich. He served as head of the Department from
1991 to 1993 . He was guest professor at the Tsinghua University in Beijing from 1993 to 1996 and at the MIT, Boston in 2001. Ludwig Gauckler and his co-workers received several national and international awards for their work on colloid chemistry for ceramic processing and high-temperature solid oxide fuel cells, rapid prototyping of ceramics $\left(\operatorname{Cercon}^{B B}\right)$, among them the Award for Real Advances in Materials from NASTS and the Federation of Materials Societies in 1994. He is Fellow of the American Ceramic Society and served as President of the scientific advisory board of the Swiss Academy of Technical Sciences (SATW) and is member of the Academy of Ceramics. His research interests include structural ceramics, high Tc-superconductors, computer-assisted modelling of thermodynamics, mixed ionic-electronic conducting oxides, and colloidal chemistry for ceramic processing. Prof. Gauckler published more than 200 scientific papers and holds 15 patents. 